\title{
Disruptions in Operant Behavior of Pigeons in Transitions across Rich and Lean Schedules of Reinforcement With and Without Advance Notice of the Lean Schedule
}

Forrest J. Toegel

Follow this and additional works at: https://researchrepository.wvu.edu/etd

\section{Recommended Citation}

Toegel, Forrest J., "Disruptions in Operant Behavior of Pigeons in Transitions across Rich and Lean Schedules of Reinforcement With and Without Advance Notice of the Lean Schedule" (2017). Graduate Theses, Dissertations, and Problem Reports. 6813.

https://researchrepository.wvu.edu/etd/6813

This Thesis is protected by copyright and/or related rights. It has been brought to you by the The Research Repository @ WVU with permission from the rights-holder(s). You are free to use this Thesis in any way that is permitted by the copyright and related rights legislation that applies to your use. For other uses you must obtain permission from the rights-holder(s) directly, unless additional rights are indicated by a Creative Commons license in the record and/ or on the work itself. This Thesis has been accepted for inclusion in WVU Graduate Theses, Dissertations, and Problem Reports collection by an authorized administrator of The Research Repository @ WVU. For more information, please contact researchrepository@mail.wvu.edu. 
Disruptions in Operant Behavior of Pigeons in Transitions across Rich and Lean Schedules of Reinforcement With and Without Advance Notice of the Lean Schedule

\title{
Forrest J. Toegel
}

\author{
Thesis Submitted \\ to the Eberly College of Arts and Sciences \\ at West Virginia University in \\ partial fulfillment of the requirements for the degree of \\ Master of Science \\ in \\ Psychology
}

Michael Perone, Ph.D., Chair

Steven G. Kinsey, Ph.D.

Claire C. St. Peter, Ph.D.

Department of Psychology

Morgantown, West Virginia

2017

Keywords: advance notice; transitions; rich and lean schedules; fixed-ratio; disruptions; pigeons Copyright 2017 Forrest J. Toegel 


\begin{abstract}
Disruptions in Operant Behavior of Pigeons in Transitions across Rich and Lean Schedules of Reinforcement With and Without Advance Notice of the Lean Schedule
\end{abstract}

Forrest J. Toegel

"Advance notice" refers to procedures in which a stimulus is provided to signal the end of an ongoing activity and the nature of the upcoming activity. Applied research has considered whether advance notice will reduce the problem behavior that sometimes occurs during transitions. Interpretation of this research is complicated by procedural variations in the type of transitions arranged, the consequences of transition-related problem behavior, the method of providing advance notice, and the measurement of the effects of advance notice. The present experiment investigated effects of advance notice using an animal model of transition-related problem behavior. Key-pecking was maintained on a two-component multiple schedule. In the "lean" component, completing a fixed-ratio produced access to food pellets for a short time; in the "rich" component, completing the ratio produced longer access. The problem behavior was measured as the disruption in pecking that occurred in the transition between rich and lean components. Advance notice was provided in some conditions by flashing the houselight in half of the ratios preceding a lean component. In the present experiment, advance notice did not reduce disruptions in pecking. Instead, when advance notice had any effect, it extended the disruptions. Additional analyses revealed that delivery of notice also disrupted responding within the ratios. The results from the present experiment are discussed in the context of applied research on advance notice. 


\section{Acknowledgements}

I would like thank Mike Perone for his guidance in experimental design, scientific writing, and computer programming - all of which were instrumental in the completion of this experiment. I am grateful to the members of my thesis committee, Mike Perone, Steve Kinsey, and Claire St. Peter for their helpful comments and suggestions on this document and their time and flexibility throughout this process. I would also like to thank the members of the Perone Lab for their help

caring for the animals and conducting sessions - especially Cory Whirtley, whose friendship and support has been invaluable. 


\section{Table of Contents}

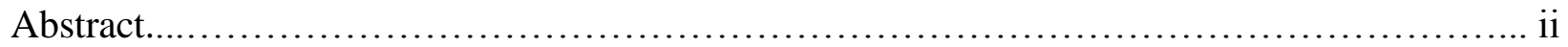

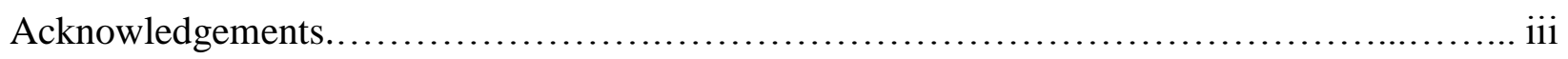

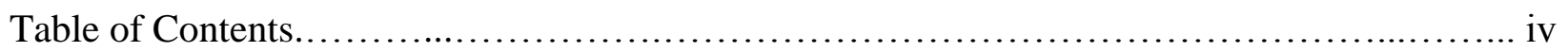

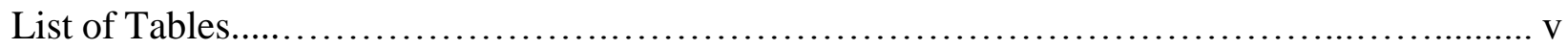

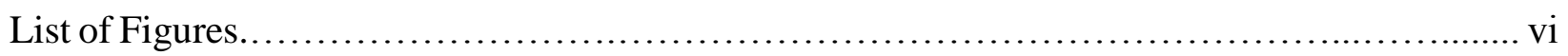

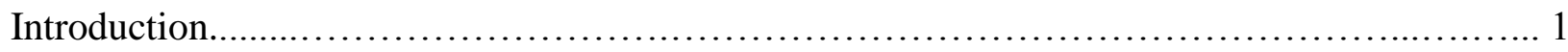

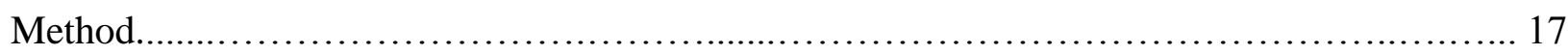

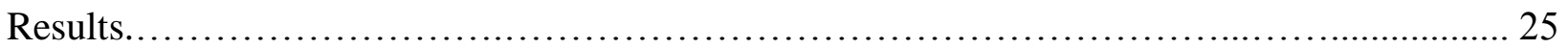

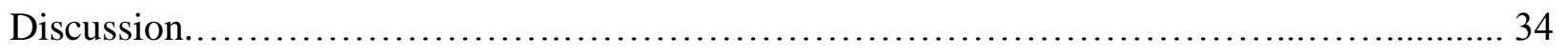

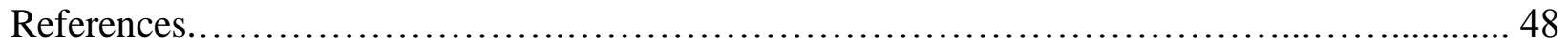

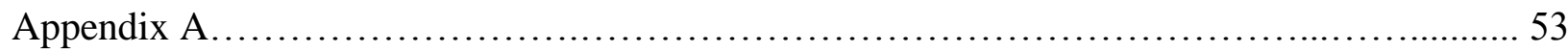

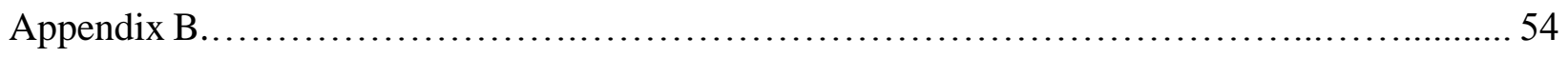

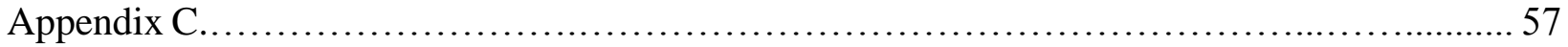

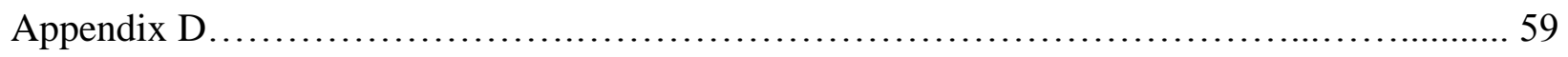

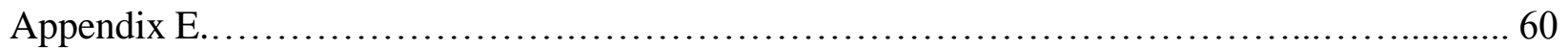

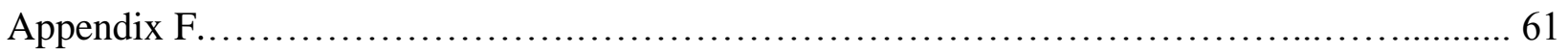




\section{List of Tables}

Table 1. For each pigeon, the terminal fixed-ratio (FR) schedule, reinforcer durations in the lean and rich components, key colors associated with the components, and measure of

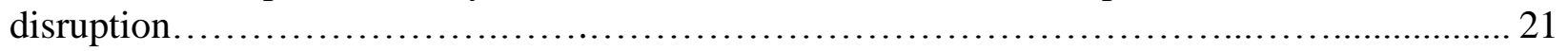

Table 2. Medians (and interquartile ranges in parentheses) of the disruption measure, expressed in $\mathrm{s}$, for each pigeon and each experimental condition. The results come from the stable 10 sessions in each condition, organized according to the type of schedule transition in which the disruption occurred: Lean to Lean, Rich to Lean, Lean with Notice to Lean, Rich with Notice to Lean, Lean to Rich, and Rich to Rich. Also shown are the order of conditions (in parentheses) and the number of sessions in each. 22

Table 3. Medians (and interquartile ranges in parentheses) of the running rates (responses per minute) for each pigeon and each experimental condition. The results come from the stable 10 sessions in each condition, organized according to the type of schedule transition in which the disruption occurred: Lean to Lean, Rich to Lean, Lean with Notice to Lean, Rich with Notice to Lean, Lean to Rich, and Rich to Rich. The order of conditions is shown in parentheses after each condition.

Table D. Percentage of transitions of each type completed by Pigeon 90 in the stable 10 sessions of each condition. The results are organized according to the type of schedule transition: Lean to Lean, Rich to Lean, Lean with Notice to Lean, Rich with Notice to Lean, Lean to Rich, and Rich to Rich. Conditions are listed in the order in which they were completed.

Table E. Percentage of the 250 possible pairs of interresponse times (IRTs) completed by Pigeon 90 before and after delivery of notice in the stable 10 sessions of conditions with advance notice. The results are organized by schedule component: Lean with Advance Notice, Rich with Advance Notice, Lean with Sham Notice, and Rich with Sham Notice. Conditions are listed in the order they were completed. 60

Table F. Results from the two-tailed paired-samples t-tests conducted to evaluate the interresponse times (IRTs) before and after notice for each pigeon and each experimental condition with advance notice. The results come from the stable 10 sessions in each condition, organized according to the component in which the IRTs were aggregated: Lean with Advance Notice, Rich with Advance Notice, Lean with Sham Notice, and Rich with Sham Notice. ... 


\section{List of Figures}

Figure 1. Left: The four types of transitions between the lean and rich components. Right: In some conditions, advance notice of an upcoming lean component is added to half of the lean components preceding the lean component and half of the rich components preceding the lean component... 24

Figure 2. Disruption for each pigeon as a function of past and upcoming lean and rich components over the last 10 sessions in each of six conditions. The headings above each column show the condition. The past component (lean or rich) is shown on the x-axis. Data points show the medians. Error bars extend from the 25 th to the 75 th percentiles.

Figure 3. Mean (+ standard error) of interresponse times (IRTs) for each pigeon before and after delivery of advance notice in the last 10 sessions of conditions with advance notice. The headings above each column show the type of component in which advance notice was delivered. The time of notice delivery in each condition (early or late) is shown on the x-axis. Asterisks identify statistically significant differences across each pair of means $(\mathrm{p}<.001=* * *, p<.01=* *$, and $\mathrm{p}$ $<.05=*)$

Figure 4. Mean (+ standard error) of interresponse times (IRTs) for each pigeon before and after sham notice in the last 10 sessions of conditions with advance notice. The headings above each column show the type of component in which sham notice was delivered. The time of notice delivery in each condition (early or late) is shown on the $\mathrm{x}$-axis. The asterisk identifies the single case in which the difference between the means was statistically significant $(\mathrm{p}<.05=*) \ldots \ldots \ldots . .33$

Figure 5. Photograph of Pigeon 90 pausing during a rich-lean transition............................... 44 


\section{Introduction}

Transitions between activities are inevitable in daily life. To engage in more than one activity, a person must, at some point, stop the activity and begin another. Transitions occur often in some therapeutic and educational settings. For example, Schmit, Alper, Raschke, and Ryndak (2000) reported that children in preschool and elementary school spent up to 25 percent of the day in transition between activities. Given the ubiquitous nature of transitions, the ability to navigate transitions smoothly and efficiently is important.

Transitions between activities have been shown to be problematic for individuals with developmental disabilities (for a review, see Brewer, Strickland-Cohen, Dotson, \& Williams, 2014; Luczynski \& Rodriguez, 2015; Williams, 2015). According to Lam and Aman (2007), in a sample of more than 300 individuals with developmental disabilities, 77 percent were reported to resist transitions or have difficulty in transitions between activities. Depending on the individual, problematic behavior evoked by transitions has included self-injury (McCord, Thomson, \& Iwata, 2001), stereotypy (Tustin, 1995), physical aggression (Waters, Lehman, \& Hovanetz, 2009), tantrums (Wilder, Chen, Atwell, Pritchard, \& Weinstein, 2006), and non-compliance with instructions given by teachers (Wilder, Nicholson, \& Allison, 2010). Although the topographies of behavior listed above differ, all are problematic because their occurrence disrupts the environment in which people teach, learn, work, play, or receive clinical intervention.

\section{Advance Notice as a Treatment to Reduce Problem Behavior}

Researchers have developed various procedures to reduce transition-related problem behavior. The present research is concerned with the procedure known as "advance notice," in which an upcoming transition is signaled by the presentation of a stimulus correlated with the end of one activity and the beginning of a new one. Flannery and Horner (1994) hypothesized 
that advance-notice procedures can reduce transition-related problem behavior by eliminating uncertainty regarding (a) the time that the current activity will end and (b) the behavior required for the upcoming activity. Although advance notice is often recommended for use with students with intellectual disabilities (e.g., Banda, Grimmett, \& Hart, 2009), field studies investigating its effectiveness have yielded mixed results.

The mixed results may stem from differences in four factors that appear to play a role in transition-related problem behavior: the type of transitions, the consequences of transitionrelated problem behavior, the method of providing advance notice, and the measurement of the effects of advance notice. Each will be discussed in turn. Some of the studies mentioned in the following sections will be discussed in further detail in the section that reviews the effectiveness of advance-notice procedures.

Type of transitions. Researchers have arranged transitions between different kinds of activities. The transition between preferred and non-preferred activities have been reported to evoke problem behavior (for reviews, see Brewer et al., 2014; Williams, 2015), but the specific activities arranged and subjects' preferences for them are not always reported. In some studies, transitions have been arranged between activities identified as preferred and non-preferred by teacher report and informal assessments (Waters et al., 2009) or by systematic preference assessments (Wilder et al. 2006). In other studies, transitions were between activities that teachers reported as "troublesome” (Ferguson et al., 2004), or activities with unknown reinforcing properties (Schmit et al., 2000; Tustin, 1995). The failure of some studies to identify the types of transitions used in research has the potential to complicate the evaluation of the advance-notice procedures' effects on transition-related problem behavior for two reasons. First, it makes it impossible to identify the effects of advance notice on any one type of transition 
(preferred to preferred, preferred to non-preferred, non-preferred to preferred, and non-preferred to non-preferred), limiting the evaluation to transitions in general. Second, it allows the possibility that the frequency of the various types of transitions could differ in the baseline and treatment phases of the experiment. In such a case, any apparent effect (or lack of effect) of advance notice could be an artifact of differences in the numbers of transitions that evoke problem behavior.

Consequences of problem behavior. Studies have differed in terms of the consequences arranged for problem behavior in the transitions. In some studies, the occurrence of problem behavior in conditions with advance notice was ignored (e.g., Tustin, 1995). In others, problem behavior or non-compliance with instructions to change activities resulted in researchers physically guiding participants to move to the location of a new activity (Schmit et al., 2000). In these studies, physical guidance prevented problem behavior from resulting in the termination or avoidance of transitions. In Water et al.'s (2009) study, consequences of problem behavior were experimentally manipulated by either providing a prompting sequence that included physical guidance to move and begin the new activity contingent for problem behavior and noncompliance with instructions or allowing the participant to terminate the transition by engaging in problem behavior and noncompliance, depending on the condition. It is likely that the variety of consequences provided for problem behavior may affect the likelihood of the occurrence of problem behavior in ways that complicate the evaluation of the advance notice procedures.

Some researchers delivered reinforcers when a participant completed a transition. In Tustin's (1995) study, a supervisor delivered praise for engaging in the new activity. For example, in Dooley, Wilczynski, and Torem's (2001) study, pretzels were provided for ending 
an ongoing activity. Ferguson et al. (2004) provided edible items to students who completed transitions within a set time limit. Waters et al. (2009) provided praise and a preferred food item for completing transitions without problem behavior. In studies in which problem behavior was followed by physical guidance (e.g., Schmit et al., 2000; Waters et al., 2009), it could be argued that the completion of transitions without problem behavior was reinforced through the elimination of the guidance.

Methods of providing advance notice. Advance notice has been operationalized in a variety of ways including combinations of visual schedules, visual cues, tones and bells, instructions, videos, and structured routines (Brewer et al., 2014). Visual schedules have provided advance notice by presenting pictures of the current and upcoming activities (Waters et al., 2009) or the order of a number of activities scheduled to occur in a day (Dooley et al., 2001). Advance notice has been provided through the use of visual or auditory cues to signal the end of an activity (turning lights off and on, showing visual representations of the amount of time remaining, ringing bells) and instructions that inform participants of the upcoming activity (Dettmer, Simpson, Myles, \& Ganz, 2000; Ferguson, Ashbaugh, O’Reilley, \& McLaughlin, 2004). Advance notice has also been delivered by providing students with instructions to end an activity and then showing the students videos of themselves engaging in the activity scheduled to occur next (Schreibman, Whalen, \& Stahmer, 2000). Finally, advance notice has been arranged by structuring routines so that individuals regularly engage in the same activities in the same order. In such a routine, instructions to end one activity might come to provide advance notice of the upcoming activity (O’Reilley, Sigafoos, Lancioni, Edrisinha, \& Andrews, 2005).

The time that advance notice is delivered in relation to the requirement to change activities might have an impact on the effects of advance notice procedures. In some studies, 
advance notice was delivered immediately before a transition (Waters et al., 2009). In other studies, advance notice was delivered minutes (Tustin, 1995), or potentially even hours (Dooley et al., 2001) before requiring an individual to end the activity.

Measurement of the effects of advance notice. The therapeutic goal of advance notice is to reduce problem behavior; however, assessments of the effectiveness of advance notice have been complicated by variations in the methods used to measure problem behavior. The system used to measure problem behavior could alter the interpretation of advance notice's effects. In some studies, problem behavior was aggregated across long observations (Dooley et al., 2001; Tustin, 1995). In other studies, problem behavior was measured only during transition periods designated in the specific study (Schmit et al., 2000; Waters et al., 2009). This variation in the measurement of problem behavior across studies can be problematic. As pointed out in Brewer et al.'s (2014) review, an advance notice procedure might relocate problem behavior that normally occurs during a transition to the point at which advance notice is delivered. If this were the case, the way that problem behavior is measured would determine whether the relocated problem behavior is recorded or not. If problem behavior was only measured during transition periods and advance notice was delivered prior to the transition period, investigators would fail to measure relocated problem behavior. Conversely, if researchers measured problem behavior over long observation periods, they would be more likely to capture relocated problem behavior, but they might also measure problem behavior that was not related to the transition at all. For example, in Tustin's study, the author reported that most stereotypy occurred when the man was required to change activities, however problem behavior was measured across 160-min observation periods that included periods of work and transitions. Although the author concluded that the advance 
notice reduced stereotypy during transitions, such a molar description of problem behavior cannot provide evidence about whether this was the case.

\section{Evidence That Advance Notice is Effective}

Brewer et al. (2014) provided several examples of situations in which advance notice was effective in reducing problem behavior. In Tustin's (1995) study, the problem behavior was stereotypy (body rocking and hand flapping) in a man with autism. Tustin reported that most stereotypy occurred when the man was required to change activities, but Tustin did not describe the actual activities or the man's preference for them. Therefore, the types of transitions that occurred were unknown. Stereotypy was measured in consecutive 2-min intervals throughout the man's workday at a vocational center where he packed materials. If stereotypy was observed at any time during an interval, the interval was marked - indicating that problem behavior occurred. Sessions lasted for approximately $160 \mathrm{~min}$ each day. A percentage was calculated by dividing the number of marked intervals by the total number of intervals in a session and multiplying by 100.

In the baseline condition, transitions occurred when a supervisor presented new materials, asked the man to begin packing the new materials, praised him if he did, removed the old materials, and ignored stereotypy. During this condition, the man engaged in stereotypy in approximately 45 percent of the daily intervals.

In the advance notice condition, transitions occurred differently. The supervisor presented new materials, asked the man if he would like to start packing the new materials, and left the area for $2 \mathrm{~min}$. During this 2-min period, the man could continue packing the old materials or could begin packing the new materials. When the supervisor returned, he praised the man if he was packing the new materials. If the man was not packing the new materials, the supervisor said 
nothing. The supervisor then removed the old materials and ignored stereotypy. This procedure meets the definition of advance notice because stimuli correlated with the end of an activity (asking the man) and the upcoming activity (new materials) were provided before the transition. The advance notice reduced the man's stereotypy from 45 percent of the intervals to 15 percent.

Schmit et al. (2000) investigated effects of a visual schedule on transition-related tantrums in a boy with autism. In this study, transitions occurred when the boy was given instructions to stop an activity and move to a new location to begin a new activity. Three different location changes separated first and second activity: moving from (a) one area of the classroom to another, (b) one classroom to another, or (c) outside of the school building to a classroom. Transitions with each change of location occurred three times per day. The activities available in each location were not reported. It was reported that the boy liked some activities (playing on the computer and being outside), but it was not clear how often transitions required the boy to stop a preferred activity and begin a non-preferred one. A tantrum was recorded if the boy screamed, hit an adult, or fell to the ground and refused to walk at any time following instructions to end an activity and beginning the next activity. A count of transitions with tantrums was kept for each change of location every day. A percentage was calculated by dividing the number of transitions with tantrums in each condition by the total number of transitions.

At the end of an activity in the baseline condition, the boy was told that it was time to go to another location (e.g., "time to go ___ "), but was not told the form of the upcoming activity. If the boy did not begin moving to the upcoming activity's location within $5 \mathrm{~s}$, he was physically guided to move. Tantrums were ignored and occurred in 61 percent of the baseline transitions across all changes in location. 
In the advance notice condition, transitions took place as in the baseline condition with two exceptions. At the end of an activity, the boy was (a) presented with a picture of the upcoming activity and (b) given instructions that specified the location and form of the upcoming activity (e.g., "time to go outside for recess"). This form of advance notice was effective in reducing the average percentage of transitions with tantrums to 16 percent across all location changes.

Although these studies provide evidence of advance notice's therapeutic efficacy, they do not support Flannery and Horner's (1994) proposal that advance notice works by reducing uncertainty in the transition between activities. First, recall that Tustin's (1995) procedure gave the participant 2 min in which to choose to stop the first activity and begin the second. It is possible that Tustin's procedure was effective because it gave the participant the option to choose when to change activities. If this was the case, then the procedure may have had nothing to do with the removal of uncertainty as posited by Flannery and Horner (1994). Second, Schmit et al. (2000) reported that, even with the advance notice procedure in place, tantrums occurred during 31 percent of the transitions that required the boy to move from outside the school building (e.g., recess) to inside the classroom. Schmit et al. (2000, p. 135) noted that the boy enjoyed being outdoors. Therefore, it is plausible that the transition-related problem behavior, in at least some transitions, was not related to uncertainty, but to the relative reinforcement available in each of the two contexts. Because preferences for activities involved in the transition were not reported, this possibility cannot be evaluated.

\section{Evidence That Advance Notice is Ineffective}

Although some studies have found advance notice to be effective in reducing transitionrelated problem behavior, Brewer et al. (2014) also identified several studies that suggest 
advance notice may be ineffective (e.g., Cote, Thompson, \& McKerchar, 2005; McCord et al. 2001; Waters et al., 2009; Wilder et al., 2006; Wilder, Zonneveld, Harris, Marcus, \& Reagan, 2007; Wilder et al., 2010). These studies differed from studies that reported positive results in the type of transitions that were arranged or in the treatment of transition-related problem behavior. For example, Waters et al. (2009) investigated the interaction between advance notice and consequences provided for transition-related problem behavior (aggression and disruption) in two boys with autism. In this study, transitions occurred when a boy was given instructions to stop a preferred activity (computer games or listening to music) and move to a different table in the room to begin a non-preferred activity (writing or coin identification). Observers recorded whether a boy engaged in aggression (e.g., hitting, kicking, biting) or disruption (e.g., throwing objects, knocking over furniture, falling on the floor and refusing to move) at any time following instructions to end the preferred activity and until the boy engaged in the non-preferred activity for at least $2 \mathrm{~min}$. A percentage was calculated by dividing the number of transitions with problem behavior by the total number of transitions and multiplying by 100 .

During transitions in the baseline condition, each boy was given instructions to end the preferred activity, but was not informed of the upcoming non-preferred activity. Each boy was then required to move and begin the non-preferred activity. Problem behavior was reinforced by reinstating the preferred activity. Problem behavior occurred in 100 percent of the transitions in the baseline condition for both boys.

In the second condition, advance notice was provided by showing each boy pictures of the preferred and non-preferred activities and requiring him to move the picture of the preferred activity into a bag - signifying that the activity was complete. Aside from the advance notice, transitions took place as described above. If a boy engaged in problem behavior, the therapist 
terminated the transition and reintroduced the preferred activity. The advance notice had no effect; as in baseline, problem behavior was observed in 100 percent of the transitions for both boys.

The third condition removed the reinforcement for problem behavior. To help the boys in the transitions, a therapist prompted each boy by giving verbal cues, gestures, or physically guiding him to end the preferred activity, move to the new location, and start the non-preferred activity contingent upon problem behavior or noncompliance with instructions. The therapist did not terminate transitions contingent upon problem behavior. Additionally, the therapist delivered praise and a preferred edible item whenever a boy completed a transition without problem behavior. This combination of extinction of problem behavior and differential reinforcement of other (non-problem) behavior was effective in reducing problem behavior to 31 percent and 17 percent of the transitions for the 2 boys.

In the final condition, the advance notice procedure was added to the extinction and DRO procedure. Problem behavior was reduced to slightly below the levels observed in the previous condition without advance notice: it occurred in 24 percent and 11 percent of transitions for the boys. The combination of the extinction and DRO procedure and advance notice procedure was effective in reducing problem behavior relative to the baseline condition, whether or not advance notice was used. Results from this study suggest that reinforcing problem behavior by allowing individuals to escape from the transition is likely to counter any potentially therapeutic effect advance notice may have.

\section{Summary of Evidence on the Effectiveness of Advance Notice}

Applied research evaluating advance notice has generated both positive and negative results. Research on advance notice has used a number of procedures that have varied in the 
types of transitions arranged, consequences provided following problem behavior, methods of providing advance notice, and measurement of the effects of advance notice. It is possible that the mixed results stem from these procedural variations. Brewer et al. (2014) identified three characteristics common to applied studies that reported advance notice to be effective. In the studies, (a) there was not a clear correlation between transition-related problem behavior and transitions from preferred activities to non-preferred activities, (b) participants were prevented from escaping transitions and (c) participants appeared to understand the signals used in the advance notice procedure. In light of these findings, Brewer et al. (2014) suggested that clinicians use advance notice when problem behavior is related to uncertainty in transitions, when problem behavior does not result in escape from transitions, and when advance notice is tailored to meet the needs of the individual. Although these recommendations may help focus attention on variables associated with the effective treatment of transition-related problem behavior, procedural variations across applied studies make it difficult to draw firm conclusions regarding advance notice's effectiveness.

\section{A Laboratory Model of Transition-Related Problem Behavior}

The high degree of variability across procedures used in applied evaluations of advance notice complicate the interpretation of advance notice's effectiveness. To assess effects of advance notice without the variability found in applied studies, it may be productive to study the procedure in a controlled environment that reliably evokes transition-related problem behavior. Perone and Courtney (1992) developed such a procedure with pigeons. Their subjects pecked a key to produce food reinforcers (access to grain) according to a multiple schedule with two components. In each component, 80 pecks were required for each reinforcer (a fixed-ratio 80 schedule; FR-80). In the component designated here as the "lean" component, completing the FR 
produced 1-s access to food. In the other, "rich," component, completing the FR produced 7-s access. These lean and rich components, each correlated with a distinctive color on the pigeon's pecking key, alternated irregularly to produce 40 transitions during each session: 10 from the lean component to the lean component (lean-lean), 10 from the lean to the rich (lean-rich), 10 from the rich to the lean (rich-lean) and 10 from the rich to the rich (rich-rich).

The problem behavior measured in the transition between components was pausing. Pausing can be considered a maladaptive on ratio-based schedules of reinforcement because rate of reinforcement is directly related to rate of responding. On a molecular level, pausing unnecessarily postpones the next scheduled reinforcer. On a molar level, pausing reduces the overall rate of reinforcement in a session. In most transitions pausing was brief, but in the richlean transitions pausing was extended. Behavior was disrupted when transitions between schedule components involved a local worsening of the conditions of reinforcement.

That extended disruptions in behavior occur in the rich-lean transition has been found to be a general phenomenon. It has been replicated with rats (Baron, Mikorski, \& Schlund, 1992), monkeys (Galuska, Wade-Galuska, Woods, \& Winger, 2005), hens (Harris, Foster, Levine, \& Temple, 2012), and humans (Williams, Saunders, \& Perone, 2011). Lean and rich schedules have been operationalized by manipulating the magnitude of reinforcers (e.g., Williams et al., 2011), the delay to reinforcers (Harris et al. 2012), the number of responses (Baron et al., 1992), or response-force requirement (Wade-Galuska, Perone, \& Wirth, 2005) associated with the production of reinforcers.

Adequacy of the animal model. Luczynski and Rodriguez (2015) raised questions about whether Perone and Courtney's (1992) procedure should be considered an analogue of problem behavior observed during transitions in applied settings. They identified three complicating 
factors. First, the lean component used in applied studies sometimes involves activities that are aversive on their own (e.g., a non-preferred activity). In basic research, both lean and rich component involve the delivery of reinforcing consequences that differ on some quantitative measure (e.g., amount of food) and the apparent aversive aspect is a product of the contrast between the juxtaposed components. Second, the form of responding and reinforcement in the lean and rich components often vary in applied studies, but not in basic studies. The behavior required in applied studies in lean and rich components is topographically distinct and may occur in different environments (rooms, tables). In basic research, a single response topography such as key pecking or lever pressing is required in both lean and rich components, and animals are not usually required to change locations. Reinforcers available in lean and rich components in applied studies are often qualitatively different and are usually part and parcel of the activity. For example, lean and rich components have involved playing with a preferred toy versus playing with a non-preferred toy (Wilder et al., 2010) or playing computer games versus completing an academic task (Waters et al., 2009) whereas basic research has generated lean and rich activities artificially (e.g., by delivering a large or small amount of food following an FR). Third, transition-related problem behavior in applied settings may produce a variety of reinforcers (e.g., access to recently terminated activity or attention) but pausing in basic laboratory experiments appears to do nothing but delay reinforcement. Therefore, Luczynski and Rodriguez argue that problem behavior in basic and applied research might be controlled and maintained by different variables.

Jessel, Hanley, and Ghaemmaghami (2016, Experiment 1) addressed these three concerns when they systematically replicated Perone and Courtney's (1992) procedure in a clinical setting with two boys. As in Perone and Courtney's (1992) procedure, a multiple schedule with rich and 
lean components was programmed. Distinct colors of carpet (and, for one boy, materials used in a sorting task) were correlated with the rich and lean components. Sessions included five components, each lasting 2 min, arranged to produce four transitions, one of each type (leanlean, lean-rich, rich-lean, rich-rich). For one boy, transitions were arranged between components in which the boy sat on a colored square of carpet and played with either a preferred item (rich component) or a non-preferred item (lean component). For the other boy, the transitions were arranged between components in which a preferred edible item was provided on an FR-1 schedule for correct responses in a sorting task (rich) or a non-preferred edible item was provided on an FR-5 schedule (lean).

The toys and edibles associated with the lean and rich components were identified via preference assessments before the experiment. Every item used in the experiment was selected at one point during the preference assessment. This suggests that the items used in lean and rich components were not aversive when presented alone, addressing Luczynski and Rodriguez's (2015) first concern.

Lean and rich components for the first boy were similar to those frequently arranged in applied studies. For this boy, the form of the response required for the activity and the form of reinforcement both differed across the lean and rich components. Components for the second boy more closely approximated those used in basic research. For this boy, the reinforcers available in the lean and rich components differed, but the form of the activity required to produce them was the same. This addresses Luczynski and Rodriguez's (2015) second concern regarding the form of responding and reinforcement in applied and basic studies.

Disruptions in behavior were measured in two ways: problem behavior and dawdling. As in basic research, problem behavior and dawdling were never directly reinforced and both 
delayed reinforcement. The fact that problem behavior was not reinforced in Jessel et al.'s (2016) study addressed Luczynski and Rodriguez's (2015) third concern about problem behavior contacting multiple, potentially reinforcing, consequences behavior in applied settings. Problem behavior was recorded when forms of aggression (e.g., hitting or kicking) or property destruction (e.g., tearing or throwing objects) were observed. Problem behavior was observed in only one of the boys. For that boy, problem behavior occurred most often in rich-lean transitions $(M=0.6$ responses per minute), less often in rich-rich $(M=0.1$ responses per minute) transitions, and never in lean-lean or lean-rich transitions. Dawdling was defined as the time between terminating one activity and beginning the next one. Dawdling was extended in rich-lean transitions for both boys. For one boy, dawdling lasted an average of $31 \mathrm{~s}$ in rich-lean transitions, and $18 \mathrm{~s}, 6 \mathrm{~s}$, and $17 \mathrm{~s}$ in lean-lean, lean-rich, and rich-rich transitions, respectively. For the other boy, dawdling lasted an average of $41 \mathrm{~s}$ in rich-lean transitions and $27 \mathrm{~s}, 17 \mathrm{~s}$, and $27 \mathrm{~s}$ in lean-lean, lean-rich, and rich-rich transitions, respectively.

Jessel et al.'s (2016) study suggests the validity of Perone and Courtney's (1992) procedure as a model of transition-related problem behavior in applied settings. The authors arranged transitions between lean and rich components that differed based on the boy's preference for the activity available or on the FR requirement and the boy's preference for the edible item available. Similar to laboratory experiments showing pausing in animals (e.g., Perone \& Courtney, 1992), pausing in humans (Williams et al., 2011), and self-injury in humans (DeLeon, Williams, Gregory, \& Hagopian, 2005), problem behavior and dawdling occurred most often in the rich-lean transitions. By arranging transitions between activities in a similar manner as in basic research and obtaining parallel results, Jessel et al.'s study supports the assertion that Perone and Courtney's procedure is a valid model of transition-related problem behavior. 


\section{The Present Experiment}

The purpose of the present experiment was to evaluate the effectiveness of advance notice using an animal model of transition-related problem behavior. The present experiment used Perone and Courtney's (1992) procedure to establish transition-related problem behavior in pigeons during transitions between lean and rich FR components. The problem behavior was behavioral disruption that occurred in the transition between components. Behavioral disruption was measured in one of two ways, depending on the pigeon. In most cases, the measure was the classic pause: the time from the start of a component until the first response on the FR. For one pigeon, disruption was measured as the time required to complete 10 percent of the FR. This second measure of disruption was created because a peculiarity in the pigeon's pattern of responding prevented the first measure from accurately describing the behavioral disruption for this pigeon.

After problem behavior was established, the advance notice was delivered by flashing the houselight after a percentage of the FR was completed in half of the components that preceded transitions to the lean component. Advance notice's effects were evaluated by comparing the behavioral disruptions in transitions between components with and without advance notice. Delivering advance notice in half of the transitions to the lean component provided a baseline from which to compare the effects of advance notice on disruptions in each pigeon and in every session. Because the Perone and Courtney (1992) procedure evokes extended behavioral disruptions in rich-lean transitions, the rich-lean transition is where advance notice's effects were predicted to be most apparent. If advance notice had a therapeutic effect, then the disruption observed in rich-lean transitions should be reduced when advance notice was delivered before the transition relative to when it was not. 
The experiment was also designed to assess whether the effectiveness of advance notice was related to the time of its presentation. To assess this possibility, advance notice was delivered either early or late, in relation to the completion of an FR component. In the Early Notice condition, notice was delivered after 30 percent of the FR was completed; in the Late Notice condition, it was delivered after 85 percent. The effects of delivering advance notice at different times in an FR component were evaluated by comparing disruptions in transitions to the lean component in the Early Notice and Late Notice conditions.

Finally, it was possible that advance notice affected behavior within FR components at the time that it was delivered. As discussed in Brewer et al. (2014), advance notice might relocate problem behavior that normally occurs during transitions to the point in time that advance notice is delivered. To assess this possibility, comparisons were made between patterns of responding that occurred immediately before and after advance notice was delivered within FR components.

\section{Method}

\section{Subjects}

Five experimentally naïve White Carneau pigeons were maintained at $80 \%( \pm 2 \%)$ of their free-feeding body weights by food deliveries during the sessions and, if necessary, supplemental feedings at least $30 \mathrm{~min}$ after the end of the session. Water and health grit were freely available in the home cage, which was kept in a temperature-controlled room with a 12:12 hr light/dark cycle. The treatment of the pigeons, in and out of the experimental sessions, complied with a protocol approved by the West Virginia University Animal Care and Use Committee. 


\section{Apparatus}

Four sound-attenuating chambers were used. Each chamber measured $37 \mathrm{~cm}$ high, $30 \mathrm{~cm}$ wide, and $32 \mathrm{~cm}$ deep. General illumination was provided by a $28-\mathrm{v}$ houselight (No.1829) located behind a translucent screen in either the lower left corner of the front panel or in the center of the chamber ceiling. Three response keys, about $2 \mathrm{~cm}$ in diameter, were arranged in a row on the front panel $24 \mathrm{~cm}$ from the floor and $9 \mathrm{~cm}$ apart, center to center. When operative, keys were illuminated from behind by $28-\mathrm{V}$ bulbs (No.1829) covered with colored caps. Food reinforcers consisted of access to pigeon food pellets (Purina Mills Nutriblend Green) through an illuminated (No.1829 bulb) 5-cm x 6-cm rectangular aperture located approximately $11 \mathrm{~cm}$ below the center key. When a reinforcer was delivered, the houselight and response keys were darkened and the food aperture lit. If a pigeon pecked a darkened key during the first second of the reinforcement cycle, the clock controlling the duration of food presentation was reset until pecking ceased for $1 \mathrm{~s}$. This ensured that the pigeon did not peck through the reinforcement cycle. The duration of the reinforcement cycle was varied to produce lean and rich schedule components. Noise from a ventilation fan on the side of the chamber was used to mask extraneous sounds. Experimental events were controlled and recorded using microcomputers connected to the chambers by a commercial interface.

\section{Procedure}

Each pigeon was trained to eat pellets from the food aperture promptly upon food delivery, and key pecking was established by way of an autoshaping procedure (see Appendix A for details). Thereafter, sessions normally were conducted 6 days per week at approximately the same time each day. Before each session, to minimize the effects of handling on behavior during the experiment, each pigeon was placed in its chamber for 5 min with the chamber lights turned 
off. The session began with the onset of the houselight and illumination of the center key. Sessions ended after 41 reinforcers were delivered or $4 \mathrm{hr}$ elapsed, whichever came first.

After responding was established, reinforcers were delivered after a fixed number of responses (FR schedule). The size of the FR was raised over a series of sessions, first in steps of 2 (FR 1 to FR 5), then in steps of 5 (to FR 50), steps of 10 (to FR 100), and steps of 20. Each FR was imposed for at least 2 sessions. The terminal FR varied across pigeons and depended on the pattern of pausing and responding as described below.

The FR was raised within the context of a multiple schedule, initially with identical FRs in two components leading to 4-s reinforcers. Each component was correlated with a key color. To evaluate each pigeon's color bias, the pair of colors was varied across sessions. For example, the following combinations were presented across 3 sessions in one of the chambers: (a) white and red, (b) white and green, (c) red and green. The three combinations were then repeated.

After the pigeon completed 2 sessions at FR 20, a pair of colors was selected for use throughout the rest of the experiment. Selection was based on patterns of pausing and responding when the key was lit each color. The two colors that were associated with the most similar patterns were selected.

After the pigeons completed 2 sessions at FR 50, the reinforcer durations in the two components were changed to create a lean component with a relatively short access to food and a rich component with relatively long access. Assignment of the key colors to the lean or rich components was decided by comparing patterns of pausing when the key was lit each color. If shorter pauses were observed in the presence of a particular color, that color was assigned to the lean component. This procedure ensured that longer pauses that might eventually take place at the beginning of the lean component could not be attributed to a color bias. 
The FR was raised until a set of schedule parameters that reliably generated extended pausing in the rich-lean transition was identified. Table 1 shows the final FR schedule, reinforcer durations, and key colors for each pigeon. The table also shows the dependent variable that was used to measure the disruption in responding, if any, in the transition between the schedule components. The conventional measure of disruption - the one used by Perone and Courtney (1992), Baron et al. (1992), Galuska et al. (2005), and Williams et al. (2011) - is the so-called postreinforcement pause, defined as the time from the onset of the schedule until the first response. This measure was used for 4 of the 5 pigeons. In Pigeon 1108, however, the pause understated the extent of the disruptions because this pigeon tended to peck the key immediately after a reinforcer and then pause. Because of this atypical response pattern, the disruption in pecking for Pigeon 1108 was measured as the time from the start of a component until 10\% of the FR was completed.

Component sequences. The two components of the multiple schedule alternated in a quasi-random fashion. Before each session, the sequence of the lean and rich components was decided using a computer program (see Appendix B for a listing of the code). The program generated a sequence of 41 components at random, with the following restrictions: (a) the sequence had to include exactly 10 transitions of each type (lean-lean, lean-rich, rich-lean, and rich-rich) and (b) no more than 3 lean or 3 rich components could be arranged in succession. As it turns out, any sequence that met these criteria began and ended with the same type of component.

After the terminal schedule parameters and measures of disruption were established, the experiment proper was begun. Table 2 shows experimental conditions for each pigeon. The order of conditions was counterbalanced across pigeons to evaluate sequence effects. The conditions 
Table 1. For each pigeon, the terminal fixed-ratio (FR) schedule, reinforcer durations in the lean and rich components, key colors associated with the components, and measure of disruption.

\begin{tabular}{lcccccccc}
\hline & & \multicolumn{2}{l}{ Reinforcer Duration $(\mathrm{s})$} & & \multicolumn{2}{c}{ Key Color } & \\
Pigeon & FR & Lean & Rich & & Lean & Rich & Measure of Disruption \\
\hline 88 & 80 & 2 & 6 & & White & Orange & Time to First Response \\
90 & 90 & 2 & 6 & & Red & Green & Time to First Response \\
1108 & 240 & 1 & 7 & & Blue & Green & Time to Complete 10\% of FR \\
1156 & 120 & 4 & 10 & & Red & Green & Time to First Response \\
1424 & 200 & 1 & 7 & & Green & White & Time to First Response \\
\hline
\end{tabular}




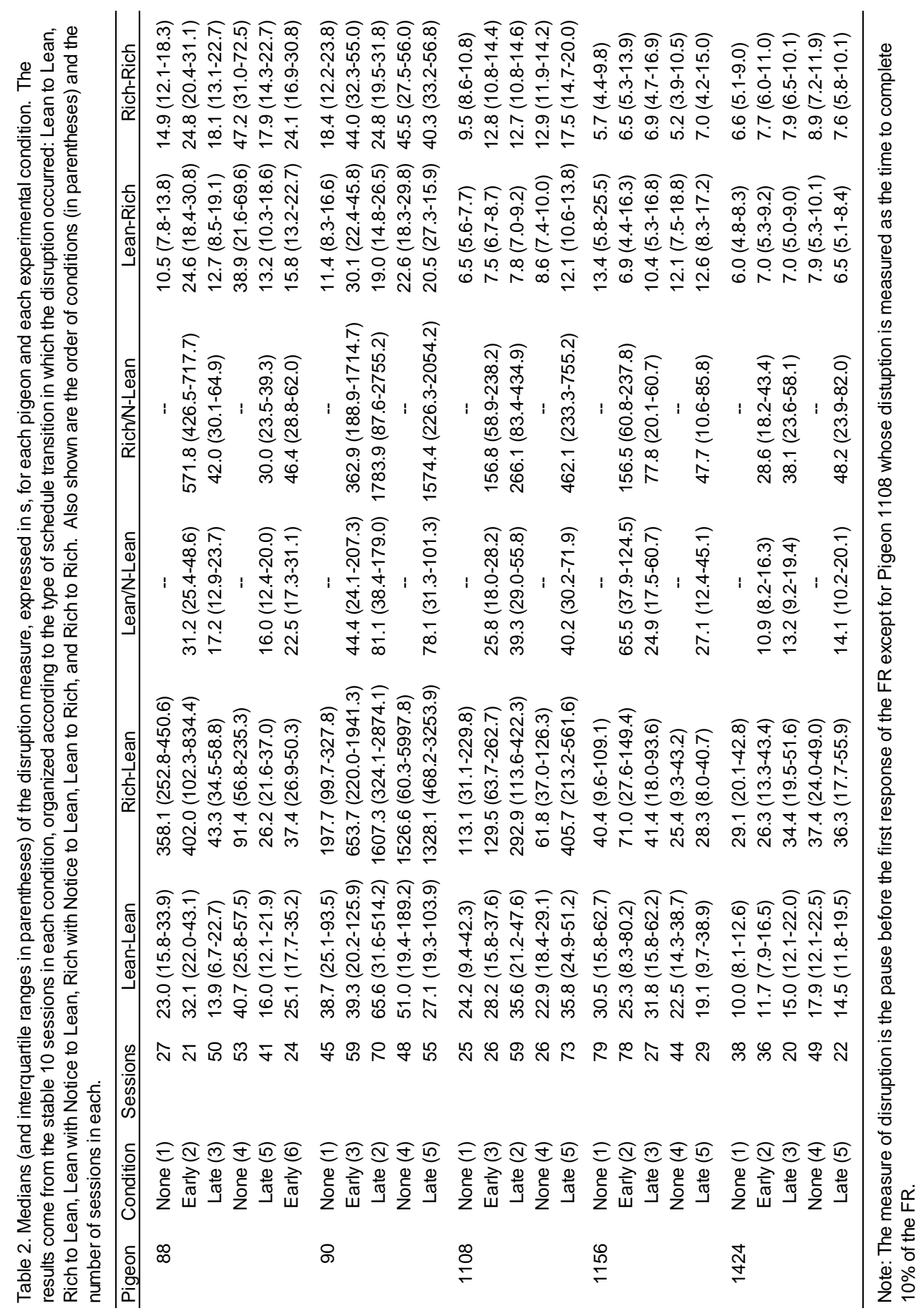


differed in terms of the presentation of a stimulus that gave advance notice of an upcoming lean schedule. The notice consisted of flashing the houselight (150 ms off, $150 \mathrm{~ms}$ on) after a percentage of the FR was completed, continuing until the end of the FR. The right half of Figure 1 illustrates how the notice was distributed across the four types of transitions between components. Only half of the lean components were preceded by the notice: This arrangement permitted comparisons of transitions with and without advance notice within a single session: half of the lean-lean transitions (lean/N-lean) and half of the rich-lean transitions (rich/N-lean) included notice. Across conditions, notice was arranged either early or late in the selected components. In the Early Notice condition, the stimulus was presented after 30 percent of the FR was completed. In the Late Notice condition, the stimulus was presented after 85 percent. As shown in Table 2, in some conditions, no notice was scheduled (No Notice condition).

To decide which specific components would include notice, a computer program was used to make the selections at random with the following restrictions: (a) notice could not be given in the first component of a session and (b) notice could not be given in more than two successive components. The program's listing is shown in Appendix C.

Each condition lasted a minimum of 20 sessions and continued until disruptions in pecking stabilized. Judgments of stability were based on disruptions in the 4 transitions in the conditions without advance notice (left panel of Figure 1) and the 6 transitions in the conditions with early or late notice (right panel of Figure 1). Each measure was treated as follows. Beginning with the $16^{\text {th }}$ session of a condition, disruptions were aggregated across a moving window of 10 sessions. The median was calculated from the aggregated disruptions in the most recent window. The first median was based on sessions 7 through 16; the second median was based on sessions 8 through 17; and so on. For each measure, when 5 consecutive medians 


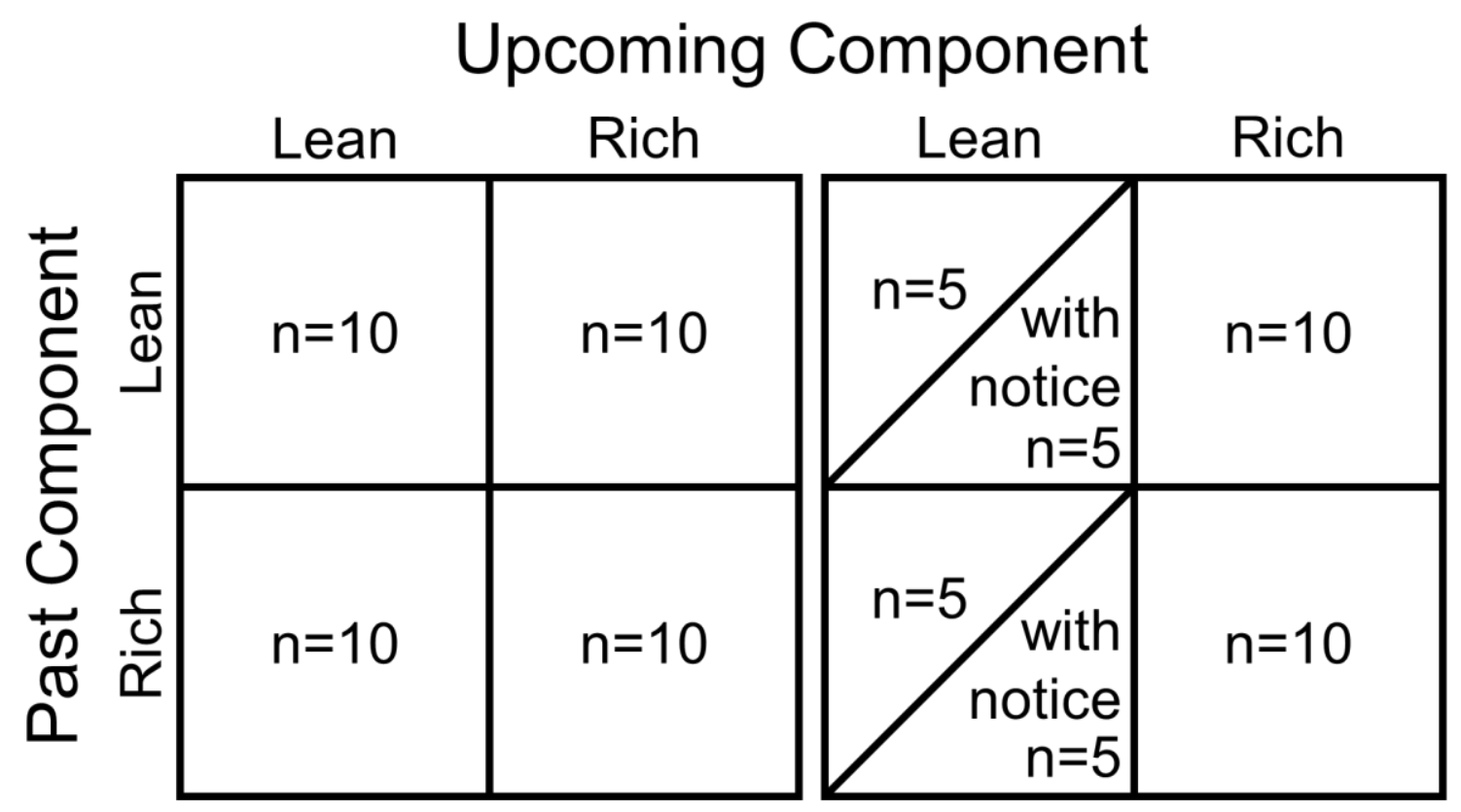

Figure 1. Left: The four types of transitions between the lean and rich components. Right: In some conditions, advance notice of an upcoming lean component is added to half of the lean components preceding the lean component and half of the rich components preceding the lean component. 
showed no increasing or decreasing trend, disruptions in pecking were judged stable. When all 4 or 6 measures were stable, the condition was ended.

\section{Results}

Unless otherwise noted, the results are based on disruptions and running response rates aggregated over the 10 stable sessions in each condition. The results were organized by the type of transition between schedule components. In conditions in which no notice was provided, this resulted in 100 measurements of disruption and responding in each type of transition (lean-lean, lean-rich, rich-lean, \& rich-rich). In conditions with advance notice, there were 100 measurements in the two transitions to the rich component (lean-rich \& rich-rich) and 50 measurements in the four transitions to the lean component (lean-lean, lean/ $\mathrm{N}-$ lean, rich-lean, and rich/N-lean). After the first condition, Pigeon 90's disruptions became so severe that the sessions regularly reached the 4 -hr time limit before 41 ratios were completed. These incomplete sessions are included among the stable sessions in all but the first condition. Because of this severe pattern of responding, the results for Pigeon 90 in those conditions are based on 92 to 295 measurements rather than 400 (see Appendix D for additional information).

Figure 2 shows the disruptions in graphic form and Table 2 shows the same information with numerical accuracy. The order of conditions displayed in the columns of the figure does not necessarily correspond to the order in which they were conducted; this information is shown in the table. The x-axis shows the component just experienced (lean or rich) and the upcoming component is shown by symbols within the panels. White circles show transitions to the lean component. Black circles show transitions to the rich component. White squares show transitions to the lean component after advance notice was provided. The data points are the medians and the error bars extend from the $25^{\text {th }}$ to the $75^{\text {th }}$ percentiles. The y-axis is scaled differently for each 


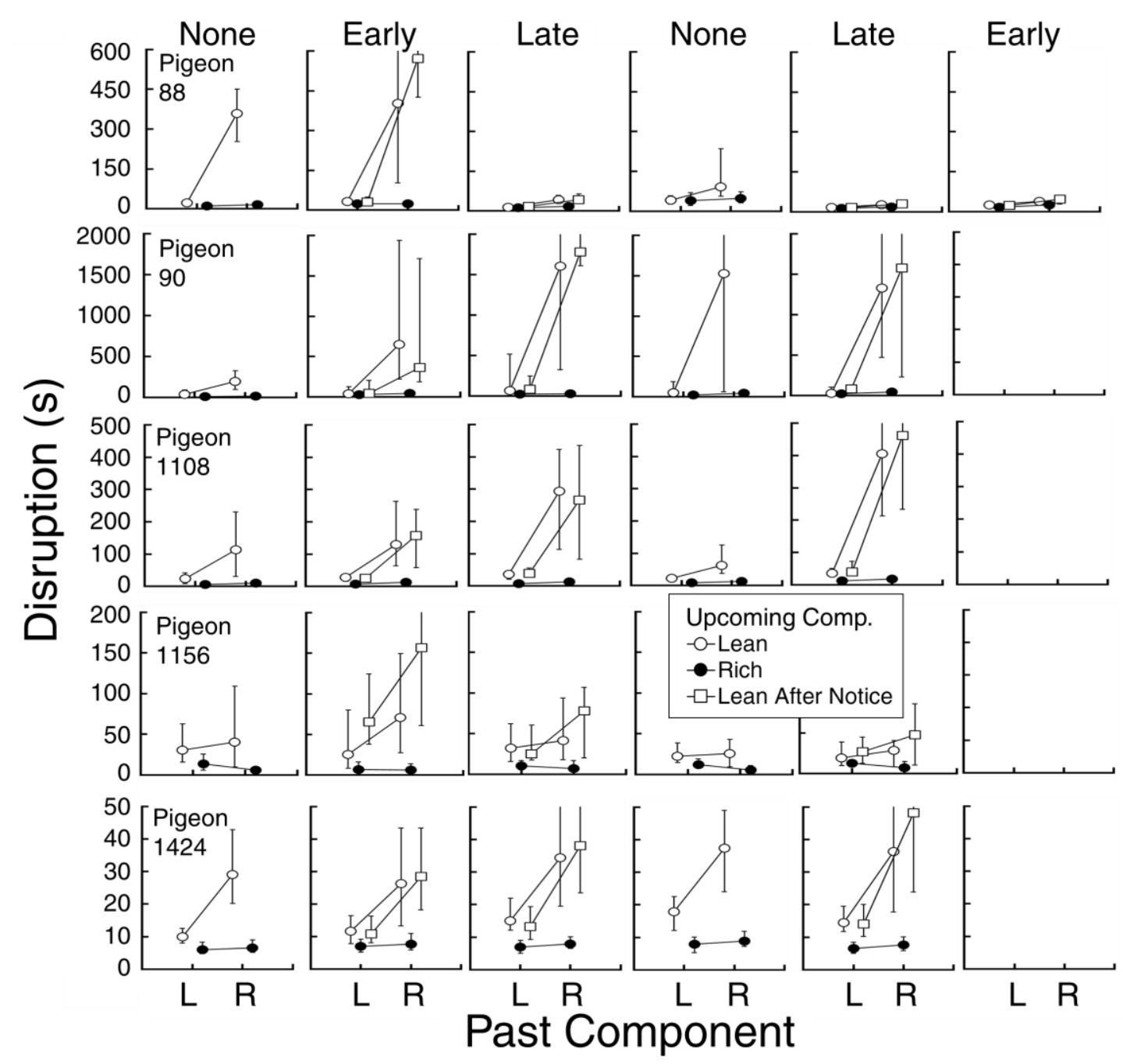

Figure 2. Disruption for each pigeon as a function of past and upcoming lean and rich components over the last 10 sessions in each of six conditions. The headings above each column show the condition. The past component (lean or rich) is shown on the x-axis. Data points show the medians. Error bars extend from the 25th to the 75th percentiles. 
pigeon to adjust for individual differences in the disruptions. In some cases, the error bars representing the $75^{\text {th }}$ percentiles extend off the figure to avoid further shrinking the scale.

In general, the procedure was successful in producing extended disruptions in the richlean transition. Perone and Courtney's (1992) findings - that disruption that occurred in the richlean transition extended beyond those observed in the other types of transitions - were replicated in every condition of the experiment. Additionally, a substantial amount of variability in disruptions was observed in the rich-lean transition, as shown by the large interquartile ranges. In some of the conditions for Pigeons 88 and 90, the scale on the y-axis makes disruptions in the rich-lean transitions appear small. In these situations, the disruptions are displayed more clearly in Table 2.

Advance notice did not reduce disruptions in the rich-lean transition. When it had any effect, it extended the disruptions. When the median disruptions with notice and without notice were compared, the median disruption was larger when notice was provided in 13 of the 16 cases. In most cases, the difference in the medians was small. Additionally, there was a substantial amount of variability in rich-lean transitions both with and without advance notice. Together, the small difference in medians and the large amount of variability observed in these transitions, make the disruptions nearly indistinguishable in most of the cases.

Across pigeons, there were no consistent differences in the effects of early and late notice. For Pigeons 90, 1108, and 1424, disruptions were larger in the Late Notice condition. For the Pigeons 88 and 1156, disruptions were larger in the Early Notice condition.

For two pigeons in the experiment, a lasting change in behavior was observed when the pigeon was exposed to the Late Notice condition for the first time. In the third condition, Pigeon 88's disruptions in the rich-lean transition stabilized at absolute values well below those 
observed in the previous conditions. These disruptions were similar when advance notice was delivered and when it was not. Despite being shorter than in previous condition, disruptions in the rich-lean transition remained large relative to those observed in the other types of transitions, as can be seen in Table 2. A similar pattern of disruptions was observed when Pigeon 88 was exposed to the No Notice and Early Notice, and Late Notice conditions for a second time.

In the second condition for Pigeon 90, disruptions in the rich-lean transition were so large that the sessions frequently reached the 4-hr time limit before 41 ratios were completed. Again, disruptions were similar with and without advance notice. These large disruptions were observed in all but the first condition. The disruptions in the rich-lean transition remained large when Pigeon 90 was exposed to the No Notice and Late Notice conditions for a second time.

Running response rates were calculated to show a more complete picture of the behavior maintained by the FR schedule. For pigeons with pausing as the measure of disruption (Pigeons $88,90,1156, \& 1424)$, running rates were calculated as the number of responses in the FR divided by the time between the first and last response of each FR. For Pigeon 1108, the measure of disruption was the time until 10 percent of an FR-240 schedule was completed, and therefore running rates were calculated as 90 percent of the FR (216 responses) divided by the time between the $24^{\text {th }}$ and $240^{\text {th }}$ response.

Table 3 shows the median running rates and $25^{\text {th }}$ and $75^{\text {th }}$ percentiles organized according to the type of transition. Running rates differed across pigeons, ranging from an average of approximately 67 (Pigeon 88) to 193 (Pigeon 1108) responses per min. The running rates were similar from one condition to the next. Within each condition, however, running rates differed depending on the type of transition. For example, median running rates were frequently lower after the disruption in the rich-lean transition than in any of the other transitions 
Table 3. Medians (and interquartile ranges in parentheses) of the running rates (responses per minute) for each pigeon and each experimental condition. The results come from the stable 10 sessions in each condition, organized according to the type of schedule transition in which the disruption occurred: Lean to Lean, Rich to Lean, Lean with Notice to Lean, Rich with Notice to Lean, Lean to Rich, and Rich to Rich. The order of conditions is shown in parentheses after each condition.

\begin{tabular}{|c|c|c|c|c|c|c|c|}
\hline Pigeon & Condition & Lean-Lean & Rich-Lean & Lean/N-Lean & Rich/N-Lean & Lean-Rich & Rich-Rich \\
\hline \multirow[t]{6}{*}{88} & None (1) & $86(76-95)$ & $74(65-83)$ & -- & -- & $82(76-87)$ & $83(74-92)$ \\
\hline & Early (2) & 86 (73-99) & $78(63-89)$ & $91(80-103)$ & $84(71-96)$ & $83(73-91)$ & $86(73-94)$ \\
\hline & Late (3) & 79 (72-89) & $64(58-73)$ & $80(69-86)$ & $63(56-70)$ & 69 (59-76) & $67(59-76)$ \\
\hline & None (4) & $68(55-81)$ & $57(47-72)$ & -- & -- & $52(45-61)$ & $52(45-62)$ \\
\hline & Late (5) & $68(61-78)$ & $60(51-70)$ & $68(58-76)$ & $62(51-67)$ & $52(43-58)$ & $49(41-54)$ \\
\hline & Early (6) & $53(49-61)$ & $47(40-56)$ & $58(51-66)$ & $48(41-52)$ & $52(46-59)$ & $50(45-58)$ \\
\hline \multirow[t]{5}{*}{90} & None (1) & $124(106-150)$ & $119(101-144)$ & -- & -- & $124(113-136)$ & $145(133-151)$ \\
\hline & Early (3) & $147(165-118)$ & $139(101-162)$ & $164(130-180)$ & $143(114-163)$ & $138(117-153)$ & $132(115-150)$ \\
\hline & Late (2) & $126(101-142)$ & $108(88-148)$ & $132(101-149)$ & $122(71-141)$ & $138(123-152)$ & $137(122-150)$ \\
\hline & None (4) & $113(84-129)$ & $97(47-108)$ & -- & -- & $119(108-137)$ & $127(100-140)$ \\
\hline & Late (5) & $139(126-155)$ & 109 (99-148) & $129(109-165)$ & $130(97-141)$ & $144(131-156)$ & $137(117-152)$ \\
\hline \multirow[t]{5}{*}{1108} & None (1) & $263(227-300)$ & $99(51-176)$ & -- & -- & 274 (259-292) & $262(250-287)$ \\
\hline & Early (3) & $239(216-255)$ & $114(79-162)$ & $239(216-254)$ & $99(66-149)$ & $239(224-250)$ & $236(219-250)$ \\
\hline & Late (2) & $228(201-261)$ & $67(44-100)$ & $217(187-248)$ & $49(35-88)$ & $245(230-260)$ & $233(219-252)$ \\
\hline & None (4) & $257(238-280)$ & $168(133-210)$ & -- & -- & $241(230-254)$ & $248(237-256)$ \\
\hline & Late (5) & $222(206-242)$ & $72(45-119)$ & $192(166-223)$ & $76(42-135)$ & $228(219-238)$ & $219(206-230)$ \\
\hline \multirow[t]{5}{*}{1156} & None (1) & $114(96-129)$ & 94 (54-124) & -- & -- & $107(95-120)$ & $96(81$ \\
\hline & Early (2) & $126(103-145)$ & $129(87-147)$ & $136(121-147)$ & $131(105-147)$ & $120(106-132)$ & $103(83-125)$ \\
\hline & Late (3) & $134(116-144)$ & $128(89-144)$ & $133(115-145)$ & $121(89-142)$ & $121(99-141)$ & $119(100-135)$ \\
\hline & None (4) & $128(111-147)$ & $119(86-133)$ & -- & -- & $125(108-135)$ & $117(103-133)$ \\
\hline & Late (5) & $124(102-140)$ & $120(113-139)$ & $126(89-144)$ & $122(67-140)$ & $124(113-136)$ & $114(96-130)$ \\
\hline \multirow[t]{5}{*}{1424} & None (1) & $190(168-208)$ & $155(120-177)$ & -- & -- & $248(228-261)$ & $245(226-259)$ \\
\hline & Early (2) & $174(148-215)$ & $118(85-153)$ & $180(158-215)$ & $113(82-182)$ & $236(217-253)$ & $229(209-251)$ \\
\hline & Late (3) & $191(164-213)$ & $117(93-158)$ & $177(156-201)$ & $122(85-161)$ & $245(226-264)$ & $226(211-247)$ \\
\hline & None (4) & $190(157-218)$ & 127 (93-164) & -- & -- & $242(219-271)$ & $231(207-254)$ \\
\hline & Late (5) & $180(156-216)$ & $134(90-171)$ & $184(143-219)$ & $114(91-153)$ & 263 (243-275) & 251 (234-273) \\
\hline
\end{tabular}

Note: Running rates are based on the type of disruption measured for each pigeon. See text for details. 
(19 of the 26 cases). Furthermore, running rates were often similar when advance notice preceded the transition and when it did not. These results suggest that the rich-lean transition affected behavior even after the disruption was removed from the running rate calculation. The finding that running rates were lower with notice and without it parallels the findings from the disruption analysis discussed above in two ways. First, when running rates were affected by a transition, it was usually the rich-lean transition. Second, advance notice did not appear to modify the effects of the rich-lean transition on running rates.

The results described so far evaluated behavior across the different types of transitions. It is possible however, that advance notice affected responding at the moment when it was delivered within an FR. To assess this possibility, the 5 interresponse times (IRTs) before and after the onset of advance notice were examined. The IRTs were aggregated over the last 10 sessions of each condition, during which there normally were 50 transitions involving notice during a lean component and 50 transitions involving notice during a rich component. The sole exception was Pigeon 90. This pigeon's failure to complete sessions yielded 20 to 80 percent of the IRTs in lean components with notice and 43 to 80 percent in rich components with notice (see Appendix E for additional information).

Figure 3 shows the mean IRT (+ the standard error) before and after notice for each pigeon. The figure is organized by condition (x-axis) and the component in which notice was delivered (lean or rich). Bars inside the panels show the mean of the aggregated IRTs before (white) and after (gray) delivery of advance notice. Error bars extend one standard error above the mean. Delivery of advance notice momentarily disrupted responding. In 22 of the 32 comparisons, the mean IRT after notice was longer than before notice. These difference were statistically significant according to two-tailed paired-samples t-tests at p-values less than .001 


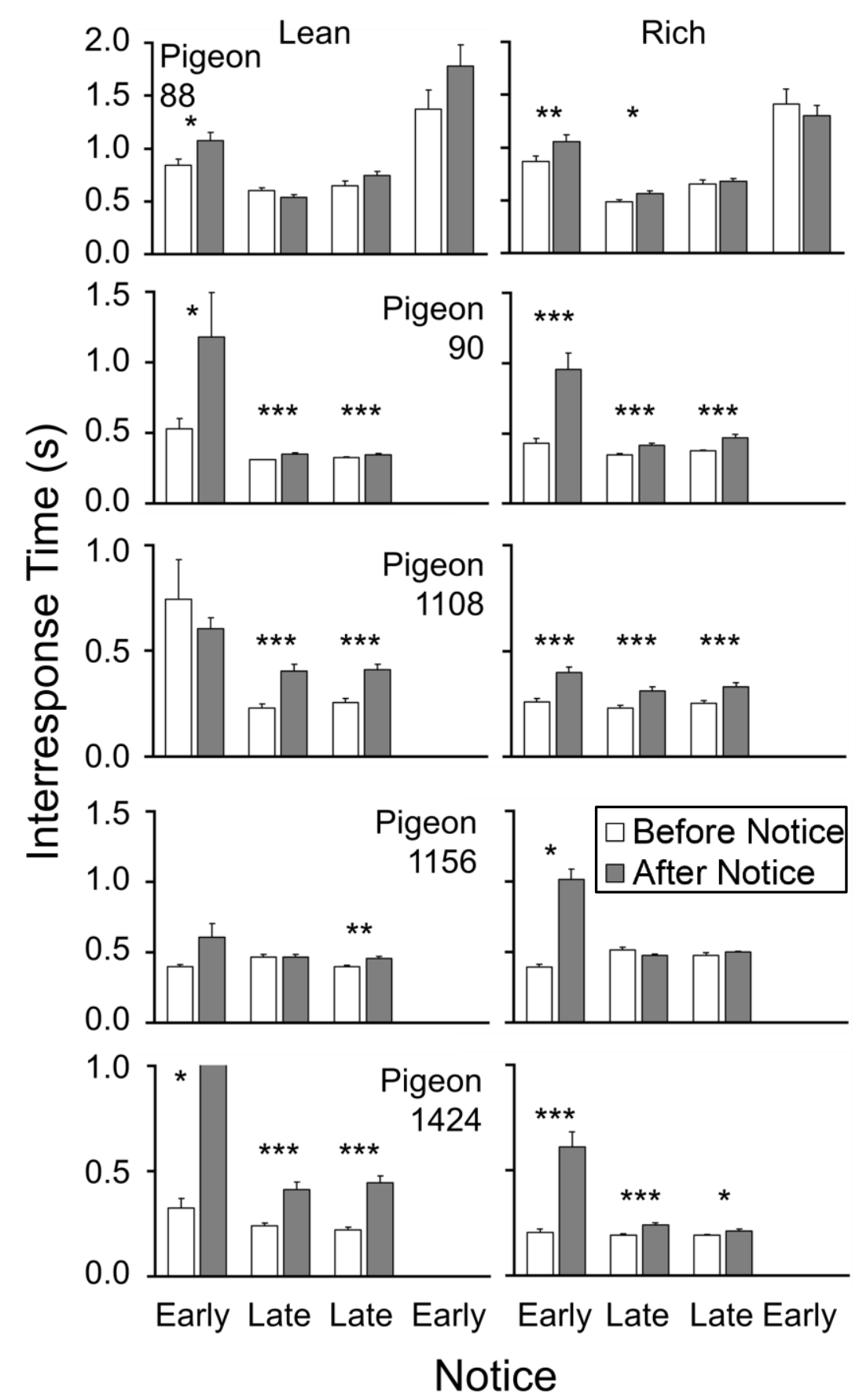

Figure 3. Mean (+ standard error) of interresponse times (IRTs) for each pigeon before and after delivery of advance notice in the last 10 sessions of conditions with advance notice. The headings above each column show the type of component in which advance notice was delivered. The time of notice delivery in each condition (early or late) is shown on the $\mathrm{x}$-axis. Asterisks identify statistically significant differences across each pair of means $(p<.001=* * *, p$ $<.01=* *$, and $p<.05{ }^{*}$ ). 
(14 cases), .01 (2 cases), and .05 (6 cases; see Appendix F for details). This local disruption by advance notice was similar in conditions with early and late notice, with 67 percent of the comparisons meeting statistical significance with early notice and 70 percent with late notice. The disruption was most reliable for Pigeons 90, 1108, and 1424 (17 of 18 cases, collectively) and less so for Pigeons 88 and 1156 (5 of 14 collective cases).

It is possible that the disruption was simply an artifact of variations in behavior that regularly occur within an FR schedule and had nothing to do with the delivery of advance notice. To evaluate this possibility, a second analysis compared IRTs in transitions to the lean component that were not preceded by advance notice. The data for this analysis come from ratios without notice, in the Early Notice and Late Notice conditions (see right panel of Figure 1, components without notice). This analysis aggregated IRTs from the same points in the ratio used in the analysis in Figure 3. In conditions with early notice, the 5 IRTs before and after the 30-percent-mark in the FR were aggregated over the last 10 sessions. In conditions with late notice, the 5 IRTs that before and after the 85-percent-mark in the FR were aggregated. In essence, then, the analysis divided the two sets of IRTs by the onset of a "sham notice."

Figure 4 shows the mean IRT (+ the standard error) before and after notice for each pigeon. Responding was not disrupted when sham notice was delivered. As before, t-tests were conducted to compare IRTs before and after sham notice (see Appendix F for details). Of the 32 comparisons, only one was significant $(\mathrm{p}<.05)$. In that case, the mean IRT after sham notice was shorter than the mean before notice; a result opposite of those found when advance notice was actually provided. It can be concluded, then, that the disruption in responding at the point in the FR in which advance notice was delivered was the result of providing notice. 


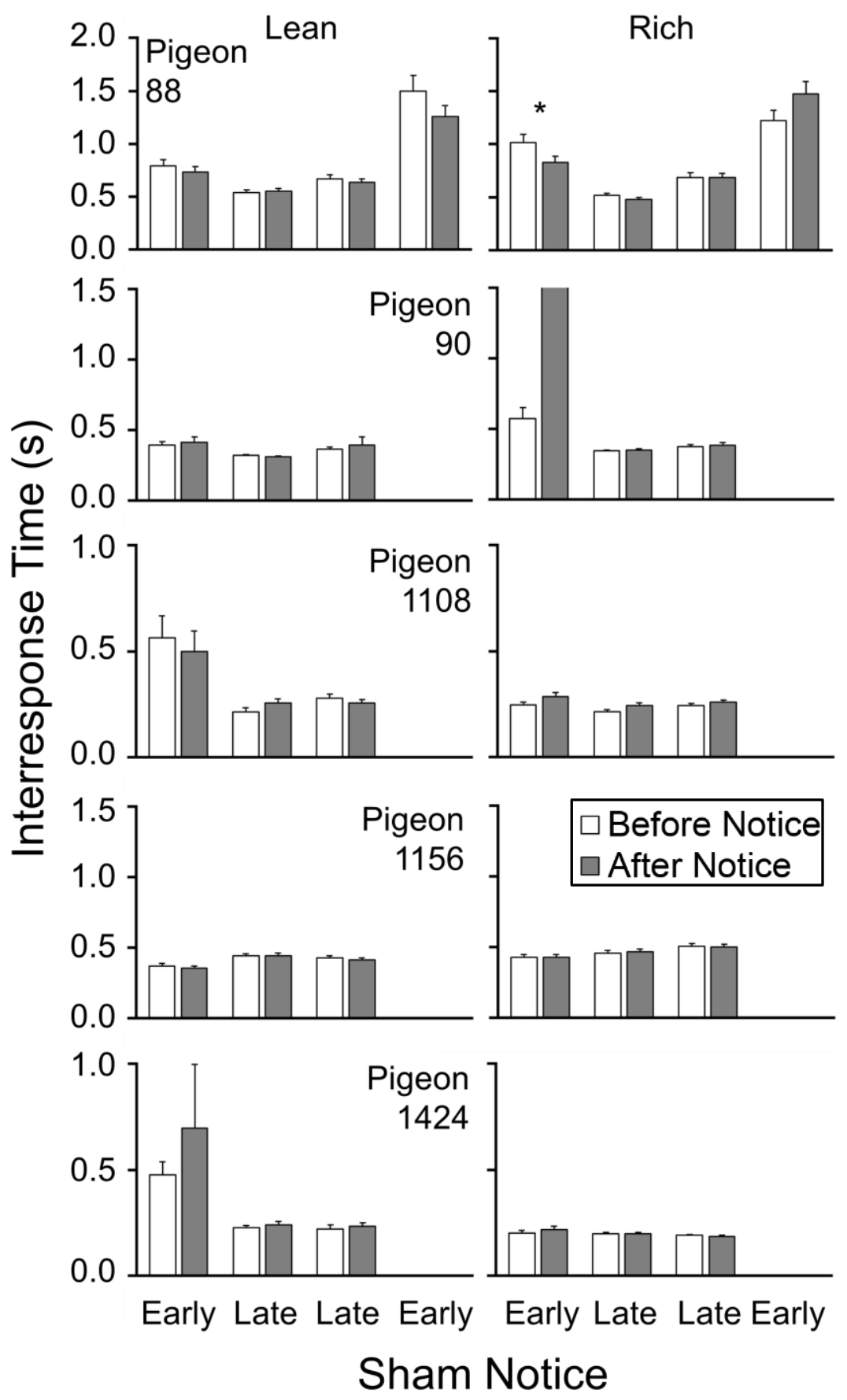

Figure 4. Mean (+ standard error) of interresponse times (IRTs) for each pigeon before and after sham notice in the last 10 sessions of conditions with advance notice. The headings above each column show the type of component in which sham notice was delivered. The time of notice delivery in each condition (early or late) is shown on the $x$-axis. The asterisk identifies the single case in which the difference between the means was statistically significant $(p<.05=*)$. 


\section{Discussion}

Providing advance notice before transitions to the lean component did not reduce transition-related disruptions. The disruptions were extended in the rich-lean transition relative to the other types of transitions when they were preceded by advance notice and when they were not. In most cases, advance notice had no detectable effect, evidenced by the close $25^{\text {th }}, 50^{\text {th }}$, and $75^{\text {th }}$ percentiles for disruptions in the rich-lean transitions with and without notice. When advance notice had a detectable effect, it was usually harmful. In 13 of the 16 cases that compared disruptions in rich-lean transitions with and without notice, median disruptions were higher when rich-lean transitions were preceded by notice than when they were not. As shown by the IRT analysis, advance notice had a reliable effect when it was delivered within the FR components; it disrupted operant behavior. The effects of advance notice within and between FR components were not systematically different when advance notice was delivered early or late in FR components. In summary, in the present experimental arrangement, advance notice was not effective in reducing transition-related problem behavior; if anything, it worsened it.

\section{Problems with Replications}

Throughout the course of the experiment, transition-related disruptions in No Notice, Early Notice, and Late Notice conditions were not always replicated for Pigeons 88 and 90. The first row of Figure 2 shows disruptions for Pigeon 88. Beginning in the third condition (third panel from the left), disruptions in all transitions decreased. Extended disruptions still occurred in the rich-lean transition relative to the other types; however, the absolute values of the disruptions were substantially lower. The decreased disruptions were observed in all subsequent conditions. 
Disruptions changed in the opposite direction for Pigeon 90. The second row of Figure 2 shows disruptions for this pigeon. Beginning in the second condition (third panel from the left; recall that Pigeon 90 was exposed to Late Notice before Early Notice), the disruptions in the rich-lean transition became so large that sessions regularly ended by reaching the 4-hr time limit before the 41 ratios were completed. Extended disruptions occurred in the rich-lean transition for Pigeon 90 in all subsequent conditions, both with and without advance notice.

There was no notable change in body weight, feeding cycle, or any other readily apparent variable associated with the changes in disruptions for either pigeon. The cause of these lasting changes is unknown.

\section{Results in the Context of Applied Research}

The finding that advance notice was not effective in reducing transition-related problem behavior challenges a body of applied research that claims otherwise. Considering that applied research on the topic has produced mixed results, however, perhaps the ineffectiveness of the present procedure should not be surprising. Applied studies that have found advance notice to be effective have differed from the present experiment in four ways: the delivery of advance notice, the measurement of problem behavior, the type of transitions that evoke problem behavior, and contingencies of reinforcement for problem and other (non-problem) behavior.

\section{Delivery of Advance Notice}

The ineffectiveness of advance notice in the present experiment may stem from problems establishing the flashing houselight as a functional signal of the upcoming lean component. The flashing houselight did function as a stimulus: As shown by the analysis of IRTs before and after its onset, the flashing houselight disrupted behavior for a short period. It is not clear however, whether the disruptive effects arose from the correlation between the flashing houselight and the 
upcoming lean component, or whether a similar effect would be produced by any stimulus change during the ratio run. Future research could investigate this ambiguity by (a) making the flashing houselight equally predictive of the rich component or (b) delivering a second kind of notice to signal the rich component. In either arrangement, if the pattern of disruption within FR components is similar for the stimuli preceding lean and rich components, it would suggest that the disruptive effects result from stimulus change, not from functional advance notice of the upcoming component.

If the flashing houselight failed to function as advance notice of the upcoming lean component, the failure might be attributed to differences in the way that advance notice was delivered in the present experiment relative to applied research. The method in the present experiment differed from some applied research in (a) the temporal relation between advance notice and the end of an activity, (b) the contiguity between advance notice and the start of the upcoming activity, and (c) the predictive value of the advance notice stimulus.

Temporal relation between advance notice and the end of an activity. In applied research, the time that advance notice was delivered in relation to the requirement to change activities varied across studies. The time of delivery was consistent within each study however, and there did not appear to be a systematic difference in the effects of advance notice when it was provided at different times in relation to the end of the ongoing activity. Still, the present experiment assessed effects of advance notice delivered at two different times in relation to the end of an FR component: after 30 percent of the FR was completed (early) or after 85 percent (late). Delivering advance notice at different times before the transition did not produce systematically different effects. Combined with the results from applied research, it is unlikely 
that variations in this aspect of the procedure can explain the mixed results found in applied studies.

Contiguity between advance notice and the start of a lean component. One aspect of the present procedure that may have negatively affected the establishment of the flashing houselight as a signal for the upcoming lean component was the lack of temporal contiguity between the flashing houselight and the beginning of the lean component. In the present procedure, the houselight flashed until the FR was completed. The houselight was turned off during the consequent food presentation ( 1 to $10 \mathrm{~s}$ ). Then the houselight was turned back on and the lean component began. It is possible that the interruption between the flashing houselight and the start of the lean component prevented it from functioning as advance notice. Future research might investigate the effects of continuing the stimulus during the reinforcer presentation.

Predictive value of the advance notice stimulus. The present arrangement of advance notice might have been ineffective because advance notice was not provided before every transition to the lean component. As reported in applied research, errors of omission and commission in treatment integrity can make a substantial difference in the effectiveness of treatment procedures (e.g., St. Peter Pipkin, Vollmer, \& Sloman, 2010). In the present experiment, all 10 instances of the flashing houselight were followed by a presentation of the lean component. Another 10 presentations of the lean component were not preceded by the flashing houselight. One might ask whether these presentations of the lean component degraded the predictive value of the flashing houselight and thereby reduced its advance notice function. 
A perfect association between the flashing houselight and the lean component would require this pair of conditional probabilities:

$$
\begin{aligned}
& \mathrm{p}(\text { Lean Component } \mid \text { Flashing Houselight })=1 \\
& \mathrm{p}(\text { Lean Component } \mid \text { No Flashing Houselight })=0
\end{aligned}
$$

In the present experiment, the conditional probabilities were:

$$
\begin{aligned}
& \mathrm{p} \text { (Lean Component | Flashing Houselight })=1 \\
& \mathrm{p}(\text { Lean Component } \mid \text { No Flashing Houselight })=.33
\end{aligned}
$$

The first probability is 1 because all 10 instances of the flashing houselight were followed by presentations of the lean component. The second probability is .33 because there were 30 components without an instance of the flashing houselight, and 10 of these were followed by presentations of the lean component. The association between the flashing houselight and the lean component was positive, indicating that the stimulus was a valid predictor of the lean component. Still, it must be acknowledged that it was an imperfect predictor, and this imperfection could conceivably have rendered the flashing houselight ineffective as advance notice of the component.

\section{Measurement of Problem Behavior}

The present procedure differed from some applied studies that have found advance notice to be effective by (a) the measurement of problem behavior in relation to transitions and advance notice and (b) the system of measurement used to evaluate problem behavior.

Measurement of problem behavior. In the present experiment, effects of advance notice were measured as the disruption in operant behavior in two places: during the transition between components and at the time that advance notice was delivered within an FR component. In applied research, the measurement of effects of advance notice has taken place at various 
times. For example, Tustin (1995) aggregated problem behavior over long observation periods that included transitions and periods of activity without transitions. This is potentially problematic because problem and non-problem behavior that is unrelated to transitions may be counted, complicating the evaluation of advance notice on transition-related problem behavior. In other cases problem behavior was measured only during transition periods as they were defined in a specific study (e.g., Schmit at al., 2000; Waters et al., 2009). This too is potentially problematic. To use the hypothetical example from Brewer et al.'s (2014) review, it is possible that advance notice could relocate problem behavior that normally occurs during a transition to the point in time before the transition at which advance notice is delivered. If it were the case that "relocated" problem behavior occurred at the delivery of advance notice and researchers measured problem behavior only during transitions, then the relocated problem behavior would be missed. By measuring problem behavior at the time of transitions and the delivery of advance notice, the present experiment was able to identify disruptive features of advance notice that may have gone undetected in applied studies.

System of measurement. The present experiment differed from applied studies in the system of measurement used to evaluate the effects of advance notice. Some applied studies counted the number of intervals in which problem behavior occurred over multiple transitions and work periods (Tustin, 1995) or the number (Schmit et al., 2000) or proportion (Waters et al., 2009) of transitions with problem behavior. Although these systems of measurement were able to identify the likelihood of problem behavior in a given period or transition, they failed to measure the magnitude of the problem behavior that occurred during transitions. This difference in measurement could have an impact on the interpretation of advance notice procedures. The pigeons in the present experiment paused in every transition, but the duration of the pausing was 
longest in the rich-lean transition. A simple counting procedure would have overlooked the substantial differences in pausing - the present measure of behavioral disruption - across the different types of transitions across rich and lean components.

\section{Types of Transitions that Evoke Problem Behavior}

Problem behavior evoked in rich-lean transitions. The discrepancies between the present findings and results from some applied studies appear to be, at least partially, the result of differences in the identification and arrangement of different types of transitions. In the present experiment, transitions were arranged between components that were known to be rich and lean before advance notice was delivered. Rich-lean transitions evoked extended disruptions whether or not advance notice was provided. The same findings have been produced in applied research when preferred (rich) and non-preferred (lean) activities were identified: Advance notice was not effective in reducing the transition-related problem behavior in the rich-lean transition (e.g., Waters et al., 2009; Wilder et al., 2010).

Problem behavior evoked in uncertain transitions. Although advance notice procedures have not been effective when transition-related problem behavior is evoked during rich-lean transitions, they have been reported to be effective when problem behavior appears to be evoked by uncertainty related to transitions (Brewer et al., 2014; Flannery \& Horner, 1994). Flannery and Horner (1994) hypothesized that uncertainty about the time and nature of transitions makes them aversive, and that advance notice can reduce the aversive function by making the transitions predictable. Because advance notice procedures have been effective only when researchers reported problem behavior to be evoked by uncertainty, Brewer et al. (2014), in reviewing research with individuals with autism, suggested that advance notice procedures should be used only when problem behavior is evoked by uncertainty and not when it is evoked 
by rich-lean transitions. A problem arises with this suggestion, however, because there is little direct evidence that uncertainty is the causal factor in the occurrence of transition-related problem behavior (Williams, 2015). Applied studies that (a) have found advance notice to be an effective treatment and (b) are compatible with the view that problem behavior is evoked by uncertainty, have often failed to identify or report the types of transitions that evoked the problem behavior (e.g., Schmit et al., 2000; Tustin, 1995). It is difficult to say whether problem behavior evoked during seemingly idiosyncratic transitions occurs because of uncertainty or whether it only appears uncertain because the types of transitions are not identified. Nonetheless, when transitions were arranged between activities known to be rich or lean, advance notice did not reduced transition-related problem behavior. The present findings contribute additional support to applied research that has found advance notice to be ineffective.

Although there is little evidence to support Flannery and Horner's (1994) hypothesis that transition-related problem behavior is caused by uncertainty, there is evidence from basic and applied research to suggest the opposite. In one phase of Perone and Courtney's (1992) experiment, pigeons completed an FR leading to 1-s access to food in the lean component of a multiple schedule and completed the same FR leading to 7-s access in the rich component. Distinct colors on the response key were correlated with the rich and lean components. Extended pausing was evoked when a rich component was followed by a lean component, and this pausing occurred in the presence of the color correlated with the lean component. In this phase of the experiment, there was no uncertainty about the next activity required of the pigeon. In another phase of Perone and Courtney's experiment, the response key was lit white in both the lean and rich components. Pausing was brief in all transitions, including the one in which the rich component was followed by the lean. There was no disruption in behavior even though there was 
complete uncertainty about the next activity. This finding runs contrary to Flannery and Horner's (1994) hypothesis. Extended pausing did not occur under the schedule with uncertainty; instead, it was observed under the schedule with certainty. This finding has been replicated in humans (Jessel et al., 2016, Experiment 2; Williams et al., 2011). Therefore, it appears that researchers and clinicians attempting to reduce transition-related problem behavior may find more success by increasing uncertainty during transitions rather than reducing it.

\section{Contingencies of Reinforcement}

Consequences of problem behavior. Variations in the treatment of problem behavior appear to contribute to contradictory findings between the present experiment and some applied research. In applied research, advance notice was effective when physical guidance prevented problem behavior and non-compliance with instructions from terminating or postponing transitions (e.g., Schmit et al., 2000; Waters et al., 2009, conditions 3 \& 4). Advance notice was not effective when problem behavior and non-compliance were directly reinforced by delaying the transition or terminating it and reinstating the preferred activity (Waters et al., 2009, conditions 1 \& 2; Wilder et al., 2010). In light of these findings, Brewer et al. (2014) recommended that clinicians using advance notice should not reinforce transition-related problem behavior by terminating or delaying transitions.

Although the present experiment did not terminate transitions and reinstate the rich component contingent upon problem behavior, there is a sense in which it may have allowed the pigeons to escape the transition temporarily. Escape is a response that removes or reduces a stimulus. Escape can be observed clearly when the removal or reduction of a stimulus is made contingent upon a single response (e.g., pecking a key). When an explicit escape contingency is absent, it is still possible for some forms of escape to occur. For example, while pausing, pigeons 
have often been reported to turn or move away from the stimulus correlated with the lean component (Cohen \& Campagnoni, 1989; Everly, Holtyn, \& Perone, 2014; Rand, 1977). An illustration of this phenomenon can be found in Figure 5, which shows a photograph of Pigeon 90 pausing during a rich-lean transition. From a subjective viewpoint, it appears that pigeons are escaping the transition by hiding from the stimulus correlated with the lean component.

It may be the case that transition-related disruptions occur because the pigeon is escaping stimuli associated with rich-lean transitions. If behavioral disruptions are a form of escape, then the results from the experiment parallel some results from applied research. In the Waters et al. (2009) study, individuals completed the transitions without problem behavior only when escape was impossible, regardless of whether advance notice was provided. In the present experiment, the problem behavior necessarily provided escape from transitions by allowing the pigeons to postpone pecking the key in the presence of the lean stimulus. It also was possible that, because the key was localized to a specific area in the chamber, the pigeon could escape the lean stimulus by turning away from the key while pausing (see Figure 5 for an example). This connection is merely speculative however, because contingencies that prevented pigeons from engaging in unauthorized escape were not investigated in this preparation. It may be possible to study the effects of advance notice when escape is prevented by providing a stimulus whose sensory properties make escape more difficult such as vibration or sound. There is direct evidence that sound can be an effective stimulus for pigeons (Murphey \& Cook, 2008; Jenkins \& Harrison, 1960).

Consequences of other (non-problem) behavior. The term "incompatible behavior" refers to a class of responses that cannot be emitted at the same time as another response. Reinforcing behavior that is incompatible with problem behavior increases the amount of time an 


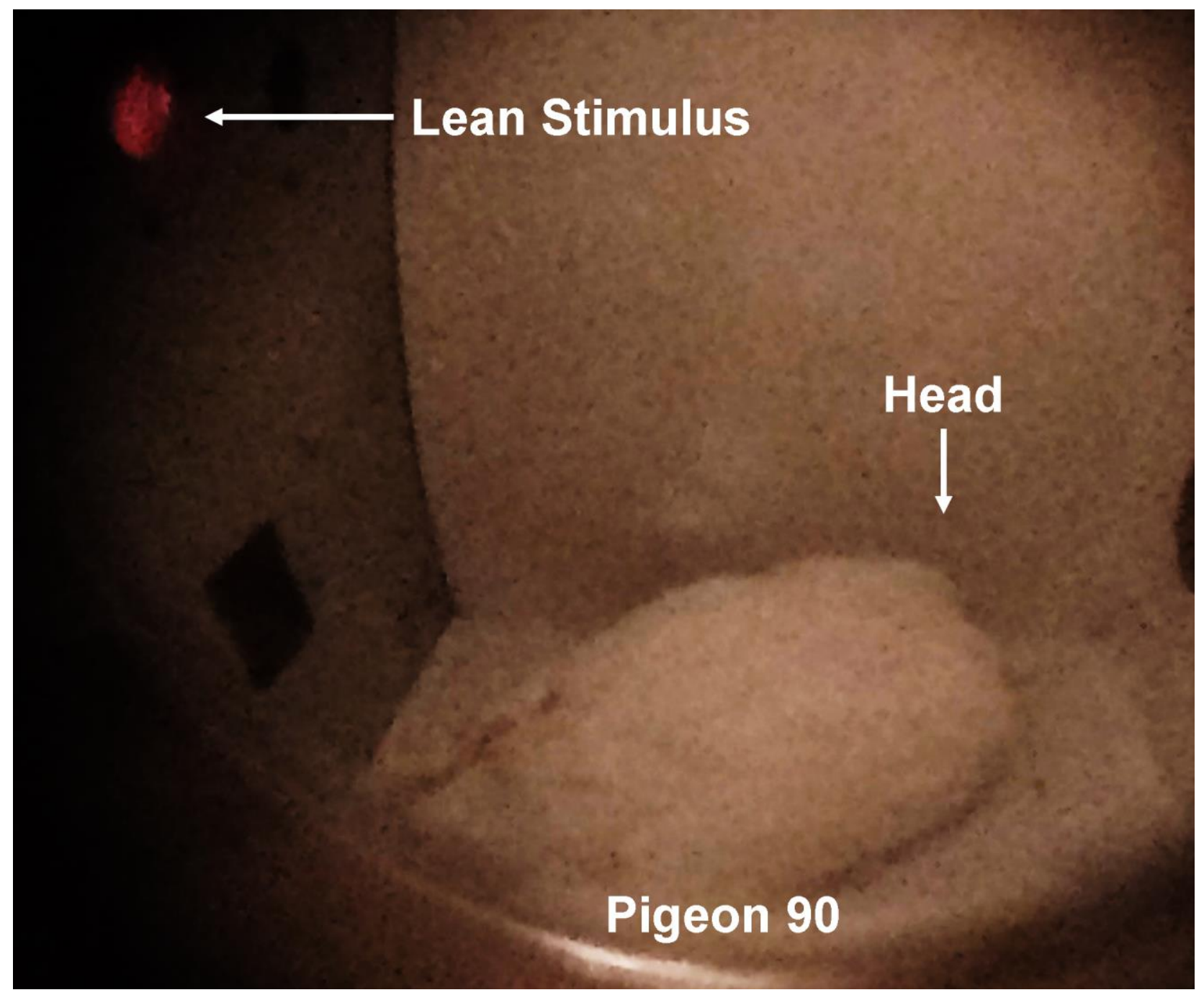

Figure 5. Photograph of Pigeon 90 pausing during a rich-lean transition. 
organism is likely to spend in non-problem behavior and therefore reduces the likelihood of problem behavior. According to a review by Knight, Sartini, and Spriggs (2015), many applied studies evaluated visual activity schedules as a component in a treatment package alongside procedures that reinforced non-problem behavior. Similarly, applied research on other forms of advance notice has provided advance notice as a component in a treatment package that included reinforcement for non-problem behavior. In some studies, reinforcers were delivered for ending an ongoing activity (Dooley et al., 2001), engaging in the next activity (Tustin, 1995), and completing transitions within a time limit (Ferguson et al., 2004). The combination of advance notice and procedures that reinforce non-problem behavior confounds the analysis of the effects of advance notice. Therefore, the extent to which advance notice alone was responsible for changes in behavior is unclear in many cases. Several authors (e.g., Bennett, Reichow, \& Woolery, 2011; Brewer et al., 2014; Knight, Sartini, and Spriggs, 2015) have suggested that a component analysis ought to be conducted to determine the extent to which advance notice is responsible for behavior change produced by treatment packages used in applied studies. Such an analysis has not yet been published; however, researchers who have examined effects advance notice without combining it with a treatment package have produced results that suggest advance notice may not contribute much to reducing transition-related problem behavior (e.g., Waters et al., 2009; Wilder et al., 2010). Consistent with Waters et al. and Wilder et al., the present experiment did not reinforce non-problem behavior and was not effective in reducing transitionrelated problem behavior.

\section{Suitability of the Animal Model}

The present experiment was designed as a controlled laboratory model to establish problem behavior and evaluate the effects of advance notice. Research using animals (Perone \& 
Courtney, 1992) and humans (DeLeon, Williams, Gregory, \& Hagopian, 2005; Williams et al. 2011) in laboratory settings and applied research with humans (Jessel et al., 2016; Waters et al., 2009) have shown that transition-related problem behavior occurs when rich-lean transitions are arranged. The present experiment established problem behavior in rich-lean transitions and created a baseline from which to assess effects of advance notice. Although advance notice has been operationalized in a variety of ways in applied research, its defining features are that a stimulus is provided that signals the end of the ongoing activity and the nature of the upcoming activity. The arrangement of advance notice in the present experiment fulfills these requirements. In the present procedure, problem behavior necessarily postponed the transition by allowing the pigeons to delay pecking on the lean component. Additionally, while each pigeon's behavior was disrupted, it was able to escape the lean stimulus by turning away from the key. Outside of the reinforcers provided by the multiple schedule, no reinforcers were provided for non-problem behavior. If considered carefully, the present results are consistent with applied research that has evaluated effects of advance notice in rich-lean transitions, allowed direct reinforcement of problem behavior with escape, and has not provided reinforcement for non-problem behavior (e.g., Waters et al., 2009; Wilder et al., 2010). Because the present experiment shares these key features and findings with applied research, it appears to have provided a valid model of transition-related problem behavior and a fair evaluation advance notice.

\section{Summary}

Regardless of the delivery of advance notice, extended disruptions were observed in the rich-lean transitions. The fact that advance notice was not effective in reducing transition-related problem behavior, and in some cases further disrupted it, might have important implications for applied treatment. If it is the case that advance notice is ineffective in reducing transition-related 
problem behavior, occasionally disrupts it further, and reliably disrupts behavior when it is delivered as it did in the present study, then advance notice should be avoided in applied settings. More research from both basic and applied settings is needed to determine the extent to which advance notice disrupts behavior when it is delivered before any conjecture should be made about when advance notice might be harmful. In any case, the findings from the present experiment lend support to applied studies that have shown that advance notice, on its own, is not effective in reducing transition-related problem behavior. By understanding what features of applied treatment are effective in reducing transition-related problem behavior, we can gain a better understanding of methods to maximize treatment effects to improve daily life for peers, teachers, caregivers, and importantly, for the people who receive applied intervention. 


\section{References}

Banda, D. R., Grimmett, E., \& Hart, S. L. (2009). Activity schedules. Teaching Exceptional Children, 41, 16-21.

Baron, A., Mikorski, J., \& Schlund, M. (1992). Reinforcement magnitude and pausing on progressive-ratio schedules. Journal of the Experimental Analysis of Behavior, 58, 377388.

Bennett, K., Reichow, B., \& Wolery, M. (2011). Effects of structured teaching on the behavior of young children with disabilities. Focus on Autism and Other Developmental Disabilities, 26, 143-152.

Brewer, A. T., Strickland-Cohen, K., Dotson, W., \& Williams, D. C. (2014). Advance notice for transition-related problem behavior: Practice guidelines. Behavior Analysis in Practice, 7, $117-125$.

Cohen, P. S., \& Campagnoni, F. R. (1989). The nature and determinants of spatial retreat in the pigeon between periodic grain presentations. Animal Learning and Behavior, 17, 39-48.

Dettmer, S., Simpson, R. L., Myles, B. S., \& Ganz, J. B. (2000). The use of visual supports to facilitate transitions of students with autism. Focus on Autism and Other Developmental Disabilities, 3, 163-169.

DeLeon, I. G., Williams, D., Gregory, M. K., \& Hagopian, L. P. (2005). Unexamined potential effects of noncontingent delivery of reinforcers. European Journal of Behavior Analysis, 6, 57-69.

Dooley, P. Wilczenski, F. L, \& Torem, C. (2001). Using an activity schedules to smooth school transitions. Journal of Positive Behavior Interventions, 3, 57-61. 
Everly, J. B., Holtyn, A. F., \& Perone, M. (2014). Behavioral functions of stimuli signaling transitions across rich and lean schedules of reinforcement. Journal of the Experimental Analysis of Behavior, 101, 201-214.

Flannery, K. B., \& Horner, R. H. (1994). The relationship between predictability and problem behavior for students with severe disabilities. Journal of Behavioral Education, 4, 157176.

Ferguson, A., Ashbaugh, R., O’Reilly, S., \& McLaughlin, T. F. (2004). Using prompt training and reinforcement to reduce transition times in a translational kindergarten program for students with severe behavior disorders. Child \& Family Behavior Therapy, 26, 17-24.

Galuska, C. M., Wade-Galuska, T., Woods, J. H., \& Winger, G. (2007). Fixed-ratio schedules of cocaine self-administration in rhesus monkeys: Joint control of responding by past and upcoming doses. Behavioral Pharmacology, 18, 229-235.

Harris, A., Foster, T. M., Levine, J., \& Temple, W. (2012). Effects of a signaled delay to reinforcement in the previous and upcoming ratios on between-ratio pausing in fixedratio schedules. Journal of the Experimental Analysis of Behavior, 98, 295-309.

Jessel, J., Hanley, G. P., Ghaemmaghami, M. (2016). A translational evaluation of transitions. Journal of Applied Behavior Analysis, 49, 1-18.

Knight, V., Sartini, E., \& Spriggs, A. D. (2015). Evaluating visual activity schedules as evidence-based practice for individuals with autism spectrum disorders. Journal of Autism and Developmental Disorders, 45, 157-178.

Lam, K. S. L., \& Aman, M. G. (2007). The repetitive behavior scale-revised: Independent validation in Individuals with autism spectrum disorders. Journal of Autism and Developmental Disorders, 37, 855-866. 
Luczynski, K. C., \& Rodriguez, N. M. (2015).Assessment and treatment of problem behavior associated with transitions. In F. D. Reed \& D. D. Reed (Eds.), Autism Service Delivery (pp. 113-149). New York: Springer.

McCord, B. E., Thomson, R. J., \& Iwata, B. A. (2001). Functional analysis and treatment of selfinjury associated with transitions. Journal of Applied Behavior Analysis, 34, 195-210.

Murphy, M. S. \& Cook, R. G. (2008). Absolute and relational control of a sequential auditory discrimination by pigeons. Behavioral Processes, 77, 210-222.

O’Reilley, M., Sigafoos, J., Lancioni, G., Edrisinha, C., \& Andrews, A. (2005). An examination of the effects of a classroom activity schedule on levels of self-injury and engagement for a child with severe autism. Journal of Autism and Developmental disorders, 35, 305-311.

Perone, M., \& Courtney, K. (1992). Fixed-ratio pausing: Joint effects of past reinforcer magnitude and stimuli correlated with upcoming magnitude. Journal of the Experimental Analysis of Behavior, 57, 33-46.

Rand, J. F. (1977). Behaviors observed during S- in a simple discrimination learning task. Journal of the Experimental Analysis of Behavior, 27, 103-117.

Rudolph, R. L. \& Harrison, R. H. (1960). Effects of discrimination training on auditory generalization. Journal of Experimental Psychology, 59, 246-253.

Schmit, J., Alper, S., Raschke, D., \& Ryndak, D. (2000). Effects of using a photographic cueing package during routine school transitions with a child who has autism. Mental Retardation, 38, 131-137.

Schreibman, L., Whalen, C., \& Stahmer, A. C. (2000). The use of video priming to reduce disruptive transition behavior in children with autism. Journal of Positive Behavior Interventions, 2, 3-11. 
St. Peter, C. C., Vollmer, T. R., \& Sloman, K. N. (2010). Effects of treatment integrity failures during differential reinforcement of alternative behavior: A translational model. Journal of Applied Behavior Analysis, 43, 47-70.

Tustin, R. D. (1995). The effects of advance notice of activity transitions on stereotypic behavior. Journal of Applied Behavior Analysis, 28, 91-92.

Wade-Galuska, T., Perone, M., \& Wirth, O. (2005). Effects of past and upcoming response-force requirements on fixed-ratio pausing. Behavioral Processes, 68, 91-95.

Waters, M. B., Lerman, D. C., \& Hovantez, A. N. (2009). Separate and combined effects of visual schedules and extinction plus differential reinforcement on problem behavior occasioned by transitions. Journal of Applied Behavior Analysis, 42, 309-313.

Wilder, D. A., Chen, L., Atwell, J., Pritchard, J., \& Weinstein, P. (2006). Brief functional analysis and treatment of tantrums associated with transitions in preschool children. Journal of Applied Behavior Analysis, 39, 103-107.

Wilder, D. A., Zonneveld, K., Harris, C., Marcus, A., \& Reagan, R. (2007). Further analysis of antecedent interventions on preschoolers' compliance. Journal of Applied Behavior Analysis, 40, 535-539.

Wilder, D. A., Nicholson, K., \& Allison, J. (2010). An evaluation of advance notice to increase compliance among preschoolers. Journal of Applied Behavior Analysis, 43, 751-755.

Williams, D. C. (2015). Challenging behavior and task transitions in autism: translating clinical phenomenology and basic behavior process. In F. D. Reed \& D. D. Reed (Eds.), Autism Service Delivery (pp. 113-149). New York: Springer. 
Williams, D. C., Saunders, K. J., \& Perone, M. (2011). Extended pausing by humans on multiple fixed-ratio schedules with varied reinforcers magnitude and response requirements. Journal of the Experimental Analysis of Behavior, 95, 203-220. 
Appendix A

\section{Preliminary Training}

\section{Magazine training}

Each pigeon was trained to eat pellets from the food aperture promptly upon delivery. When the pigeon was first placed into the chamber, the food was available through the lit aperture until the pigeon ate for at least $15 \mathrm{~s}$. Thereafter the food was presented at variable intervals. Initially, presentations lasted $15 \mathrm{~s}$, and the interval between presentations varied around a mean of $15 \mathrm{~s}$. Over one or two sessions, the duration of the food presentations was gradually reduced to $4 \mathrm{~s}$, and the mean interval between presentations was raised to $60 \mathrm{~s}$. Magazine training continued until the pigeon ate from the food aperture within 1 or $2 \mathrm{~s}$ after 5 consecutive food deliveries.

\section{Response acquisition}

An autoshaping procedure was used to establish pecking on the center key. At the beginning of a session, the houselight was turned on and remained on throughout the session except during food presentations. A trial began by lighting the response key white. After $8 \mathrm{~s}$, the key was darkened and food was presented for $4 \mathrm{~s}$. If the pigeon pecked the key while it was still lit, food was presented immediately and the key was darkened. The trials were separated by intervals averaging $60 \mathrm{~s}$ (range $45 \mathrm{~s}-75 \mathrm{~s}$ ). The procedure was continued until the pigeon pecked the lit key on 10 consecutive trials; depending on the pigeon, this required 25 to 72 . Thereafter, another 10 reinforcers were contingent solely on a key peck (i.e., an FR-1 schedule was programmed). 


\section{Appendix B}

\section{Software Used to Generate Sequences of the Two Multiple-schedule Components}

Module ComponentGenerator

' To get a sequence, write this code

' GetComponentSequence( $x x x)$ where $x x x$ is the name of the

' integer array that will contain the sequence

' The sub uses elements 1 through 41 of the array, so an upper

' bound of 41 would be suitable. For example, if the array is

' declared at the modular level in the main code, the declaration statement

' might be: Dim m_intComponents(41) as Integer

' and the call to fill the this array with a fresh set of components would be

' GetComponentSequence(m_intComponents)

' For additional details, see comments in the Public Sub GetComponentSequence

, below

' M. Perone

' WVU Psyc Dept

' January 24, 2015

Public Sub GetComponentSequence(ByRef intSequence() As Integer)

' sub to generate sequences of components

' The probability that the sequence starts (and ends) with a rich comp $=.5$

' The probability that the sequence starts (and ends) with a lean comp $=.5$

' Key to sequences:

' Lean $=1$

' rich $=2$

' The program ensures that there are exactly 10 each of the 4 possible

' transitions: L-L, L-R, R-L, R-R.

' There are no more than $3 \mathrm{R}$ or $3 \mathrm{~L}$ in a row.

Dim intoldRand(20) As Integer

Dim intRandCount As Integer, intRandNum As Integer

Dim blnoK As Boolean, blnFlip As Boolean

' if blnflip is true, we'll invert components so sequence starts w/rich comp;

' otherwise sequences starts w/lean.

' get a number between 1 and 2

Randomize()

If $(\operatorname{Int}((2-1+1) * \operatorname{Rnd}()+1))=2$ Then blnflip = True Else blnflip = False

' Generate a random intSequence of 21 zeros, 20 ones,

' with the constraint that the first and last numbers be zeros Do

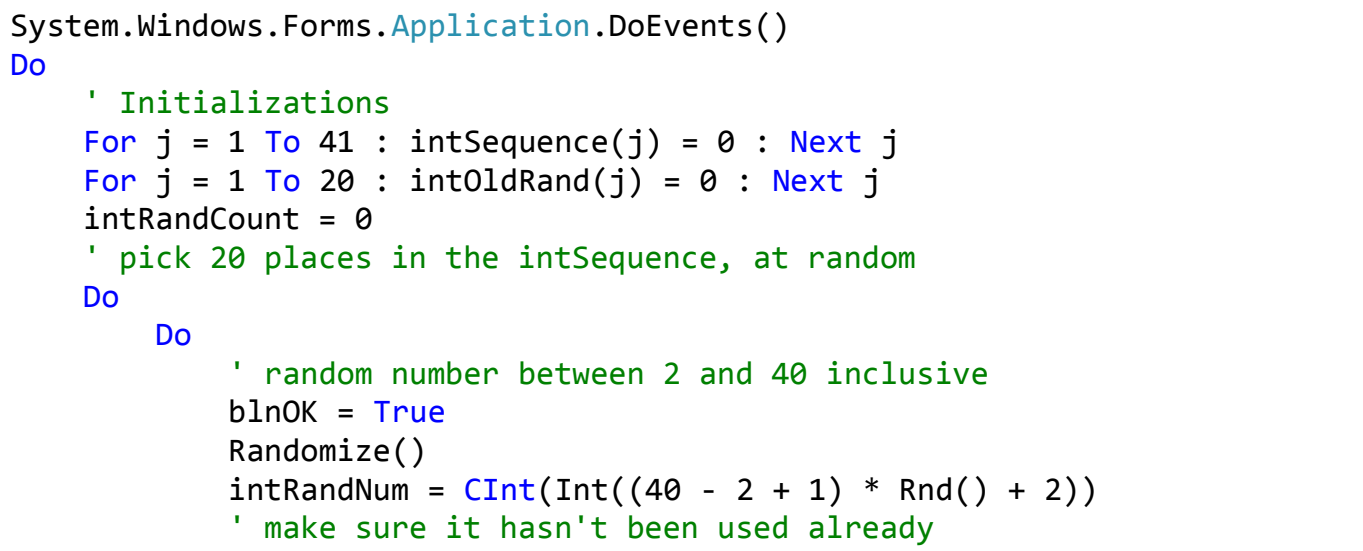




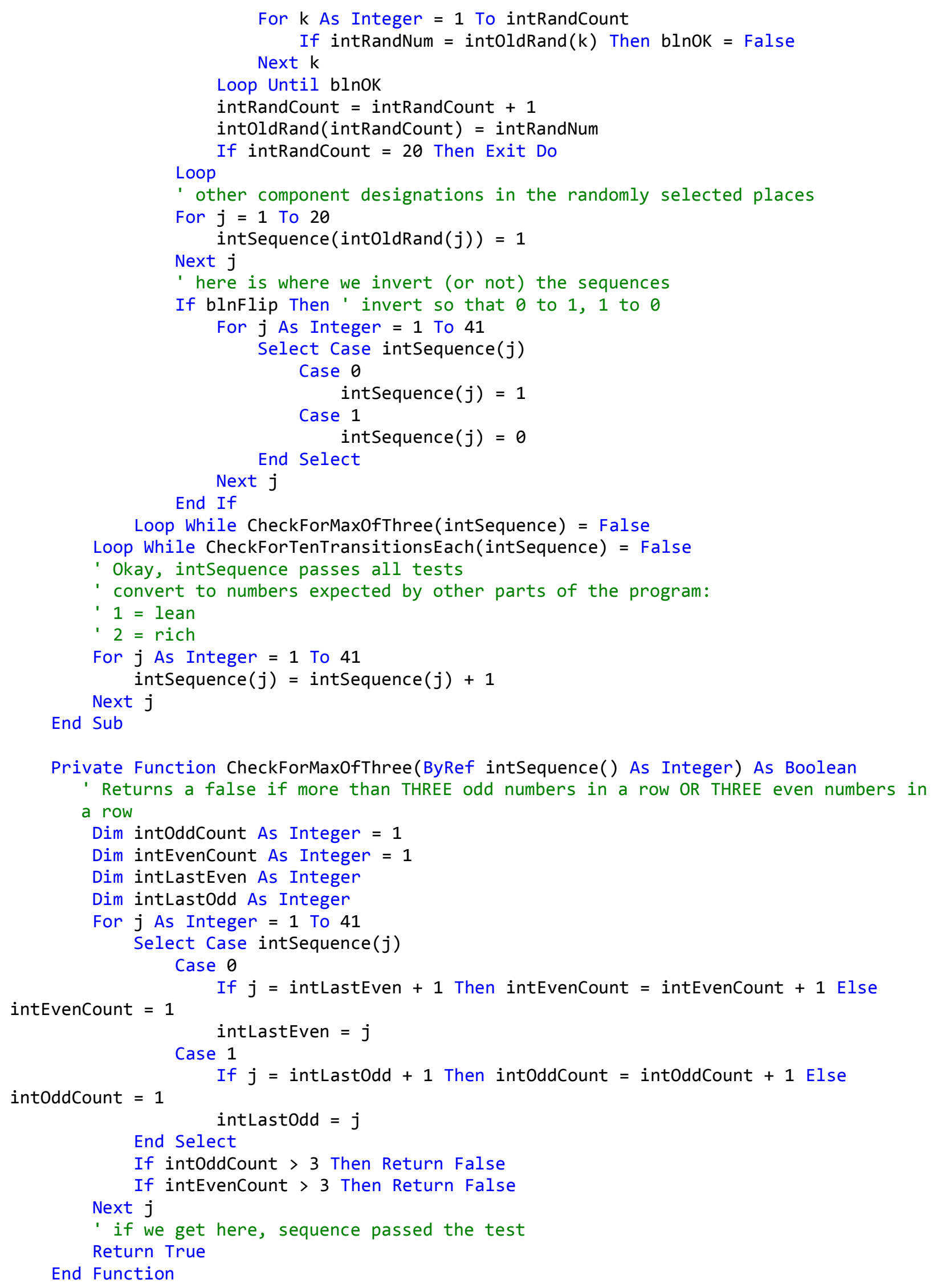


Private Function CheckForTenTransitionsEach(ByVal intSequence() As Integer) As Boolean

' now check to see that there are exactly 10 of each transition type

'(if not, we'll reject this sequence by returning a false)

Dim intTrans(4) As Integer, intTotal As Integer

For $j$ As Integer $=2$ To 41

Select Case intSequence $(j)$

Case 0

Select Case intSequence $(j-1)$

Case $\theta$ ' $\theta-\theta$

$\operatorname{intTrans}(1)=\operatorname{intTrans}(1)+1$

Case 1 ' 1-0

End Select

$\operatorname{intTrans}(3)=\operatorname{intTrans}(3)+1$

Case 1

Select Case intSequence $(j-1)$

Case 0 ' 0 - 1

$\operatorname{intTrans}(2)=\operatorname{intTrans}(2)+1$

Case 1 '1-1

End Select

$\operatorname{intTrans}(4)=\operatorname{intTrans}(4)+1$

Next $j$

End Select

For $j$ As Integer $=1$ To 4

intTotal $=$ intTotal + intTrans $(j)$

Next $j$

If intTotal $く 40$ Then Return False ' fatal error - should be exactly 40 transitions

For $j=1$ To 4

If intTrans $(j)<10$ Then Return False

Next $j$

Return True

End Function

End Module 


\section{Appendix C}

\section{Software Used to Decide Which Components Would Have Notice}

Module AdvanceNotice

' M. Perone, WVU Psyc Dept

' July 25, 2015

Public Sub AddAdvanceNotice(ByVal intSequence() As Integer)

' expects an array with upper limit of 41 and consisting of 1 's and 2's

' it changes five 1 's to 3 's and five 2 's to 4 's

' a 3 means a lean component with advance notice of another lean (so this is in a LL transition)

' a 4 means a right component with advance notice of a lean (so this is in a RL transition)

' NOTE: this calls the boolean function NoMoreThanTwoConsecutiveNotices

Dim FlipCoin As New Random ' to generate a random number

Dim intLL As Integer ' to count LL with added advance notice

Dim intRL As Integer ' to count RL with added advance notice

Do

' reset variables to initial state

intLL $=0$

intRL $=0$

For $j$ As Integer $=1$ To 41

If intSequence $(j)=3$ Then

End If

intSequence $(j)=1$

If intSequence $(j)=4$ Then

intSequence $(j)=2$

End If

Next

' let's get to work

For $\mathrm{j}$ As Integer $=3$ To 41

we start at 3 so that advance notice cannot be added to first component.

If intSequence $(j)=1$ Then

Select Case intSequence $(j-1)$

Case 1 ' 1-1 ie LL

' flip a coin to see if we will add advance notice to this transition

' but only do it 5 times

If intLL $<5$ And FlipCoin. $\operatorname{Next}(1,3)=1$ Then

' note: FlipCoint.Next $(1,3)$ returns a random integer, either 1 or 2

notice intSequence $(j-1)=3$ ' Lean component with advance

End If

intLL $+=1$

Case 2 ' 2-1 ie RL

transition

' flip a coin to see if we will add advance notice to this

' but only do it 5 times

If intRL $<5$ And FlipCoin. $\operatorname{Next}(1,3)=1$ Then

intSequence $(j-1)=4$ ' Rich component with added notice

intRL $+=1$

End If

End Select

End If

Next $j$ 
If intLL $=5$ And intRL $=5$ And NoMoreThanTwoConsecutiveNotices(intSequence)

Then

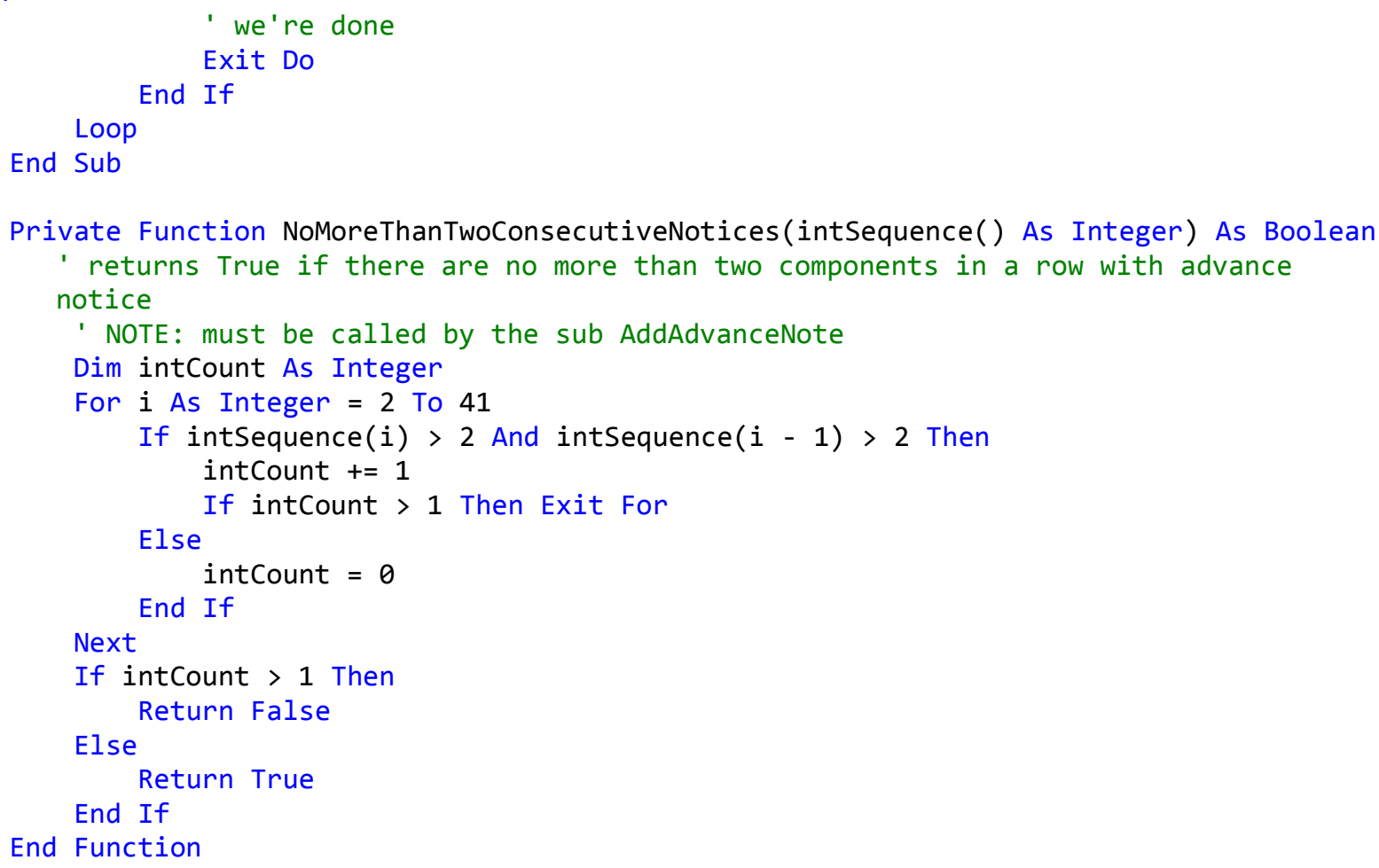




\section{Appendix D}

Table D. Percentage of transitions of each type completed by Pigeon 90 in the stable 10 sessions of each condition. The results are organized according to the type of schedule transition: Lean to Lean, Rich to Lean, Lean with Notice to Lean, Rich with Notice to Lean, Lean to Rich, and Rich to Rich. Conditions are listed in the order in which they were completed.

\begin{tabular}{lcccccc}
\hline Condition & Lean-Lean & Rich-Lean & Lean/N-Lean & Rich/N-Lean & Lean-Rich & Rich-Rich \\
\hline None & 100 & 100 & -- & -- & 100 & 100 \\
Late & 50 & 58 & 56 & 48 & 54 & 61 \\
Early & 60 & 70 & 78 & 78 & 76 & 76 \\
None & 23 & 23 & -- & -- & 23 & 23 \\
Late & 28 & 20 & 18 & 36 & 32 & 28 \\
\hline
\end{tabular}




\section{Appendix E}

Table E. Percentage of the 250 possible pairs of interresponse times (IRTs) completed by Pigeon 90 before and after delivery of notice in the stable 10 sessions of conditions with advance notice. The results are organized by schedule component: Lean with Advance Notice, Rich with Advance Notice, Lean with Sham Notice, and Rich with Sham Notice. Conditions are listed in the order they were completed.

\begin{tabular}{|c|c|c|c|c|}
\hline \multirow[b]{2}{*}{ Condition } & \multicolumn{2}{|c|}{ Advance Notice } & \multicolumn{2}{|c|}{ Sham Notice } \\
\hline & Lean & Rich & Lean & Rich \\
\hline Late & 60 & 54 & 54 & 60 \\
\hline Early & 80 & 80 & 62 & 76 \\
\hline Late & 20 & 46 & 28 & 26 \\
\hline
\end{tabular}




\section{Appendix F}

Table F. Results from the two-tailed paired-samples t-tests conducted to evaluate the interresponse times (IRTs) before and after notice for each pigeon and each experimental condition with advance notice. The results come from the stable 10 sessions in each condition, organized according to the component in which the IRTs were aggregated: Lean with Advance Notice, Rich with Advance Notice, Lean with Sham Notice, and Rich with Sham Notice.

\begin{tabular}{|c|c|c|c|c|c|c|c|c|c|c|c|c|c|}
\hline \multirow{3}{*}{$\begin{array}{c}\text { Pi- } \\
\text { geon }\end{array}$} & \multirow{3}{*}{$\begin{array}{c}\text { Condi- } \\
\text { tion }\end{array}$} & \multicolumn{6}{|c|}{ Advance Notice } & \multicolumn{6}{|c|}{ Sham Notice } \\
\hline & & \multicolumn{3}{|c|}{ Lean } & \multicolumn{3}{|c|}{ Rich } & \multicolumn{3}{|c|}{ Lean } & \multicolumn{3}{|c|}{ Rich } \\
\hline & & $t$ & $d f$ & $p$ & $t$ & $d f$ & $p$ & $t$ & $d f$ & $p$ & $t$ & $d f$ & $p$ \\
\hline \multirow[t]{4}{*}{88} & Early & -2.65 & 249 & .009 & -2.40 & 249 & .017 & 0.73 & 249 & .463 & 2.12 & 249 & .035 \\
\hline & Late & 1.73 & 249 & .084 & -2.18 & 249 & .030 & -0.44 & 249 & .660 & 1.26 & 249 & .208 \\
\hline & Late & -1.65 & 249 & .100 & -0.55 & 249 & .580 & 0.74 & 249 & .463 & 0.03 & 249 & .978 \\
\hline & Early & -1.57 & 249 & .118 & 0.71 & 249 & .481 & 1.28 & 249 & .203 & -1.66 & 249 & .099 \\
\hline \multirow[t]{3}{*}{90} & Early & -2.02 & 199 & .044 & -4.30 & 199 & .000 & -0.44 & 154 & .664 & -0.99 & 189 & .321 \\
\hline & Late & -5.83 & 149 & .000 & -4.51 & 134 & .000 & 1.65 & 134 & .102 & -0.63 & 154 & .530 \\
\hline & Late & -3.33 & 49 & .002 & -3.41 & 114 & .001 & -0.54 & 69 & .592 & -0.45 & 64 & .653 \\
\hline \multirow[t]{3}{*}{1108} & Early & -5.03 & 249 & .466 & -3.92 & 249 & .000 & -1.56 & 249 & .559 & -1.73 & 249 & .077 \\
\hline & Late & 0.73 & 249 & .000 & -4.63 & 249 & .000 & 0.59 & 249 & .119 & -1.78 & 249 & .086 \\
\hline & Late & -4.36 & 249 & .000 & -3.88 & 249 & .000 & 0.75 & 249 & .456 & -1.00 & 249 & .320 \\
\hline \multirow[t]{3}{*}{1156} & Early & -2.06 & 249 & .041 & -5.24 & 249 & .000 & 0.26 & 249 & .793 & 0.57 & 249 & .567 \\
\hline & Late & -0.50 & 249 & .619 & 1.28 & 249 & .200 & -0.10 & 249 & .923 & -0.40 & 249 & .687 \\
\hline & Late & -2.86 & 249 & .005 & -0.78 & 249 & .438 & 0.73 & 249 & .466 & 0.18 & 249 & .860 \\
\hline \multirow[t]{3}{*}{1424} & Early & -2.29 & 249 & .023 & -5.58 & 249 & .000 & -0.71 & 249 & .480 & -0.76 & 249 & .450 \\
\hline & Late & -4.44 & 249 & .000 & -4.30 & 249 & .000 & -0.72 & 249 & .471 & 0.05 & 249 & .958 \\
\hline & Late & -6.49 & 249 & .000 & -2.33 & 249 & .020 & -0.56 & 249 & .578 & 0.60 & 249 & .550 \\
\hline
\end{tabular}

Note: The results are based on the pairs of IRTs before and after notice in the stable 10 sessions of each condition. For most pigeons, results are based on the 250 pairs of IRTs before and after notice. For Pigeon 90 , results are based on fewer pairs of IRTs because fewer ratios were completed during stable sessions. 